NBC Operation Manual Including the

Multi-position Add-A-Source Function

H. O. Menlove

L. A. Foster

J. Baca 


\section{CONTENTS}

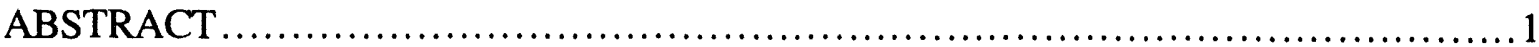

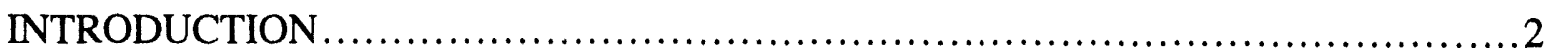

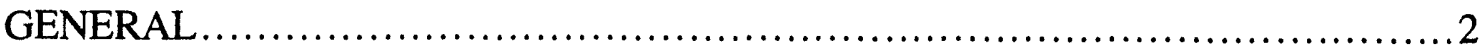

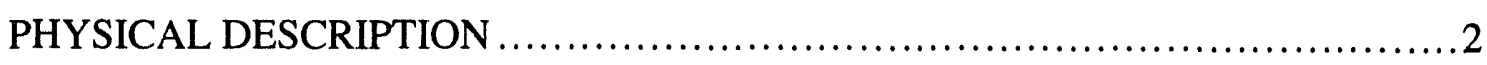

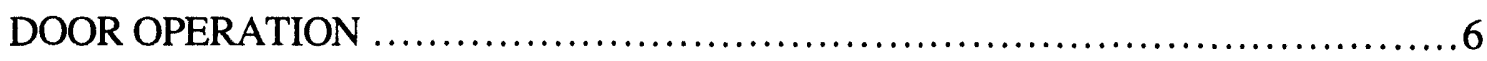

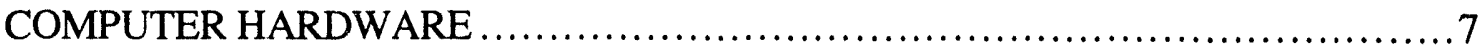

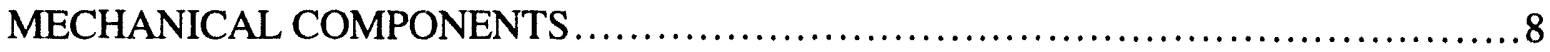

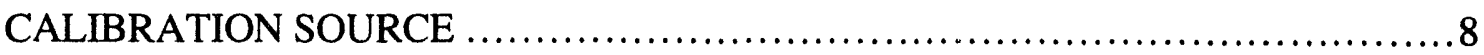

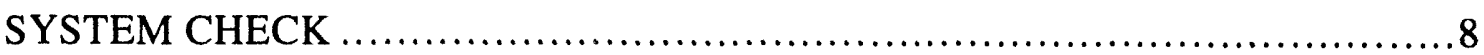

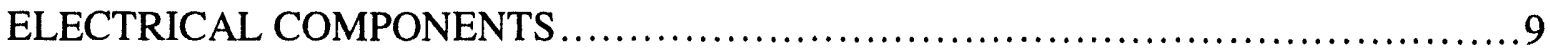

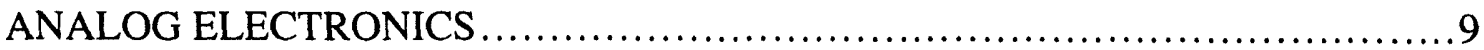

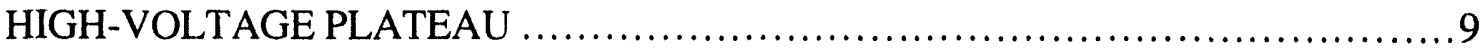

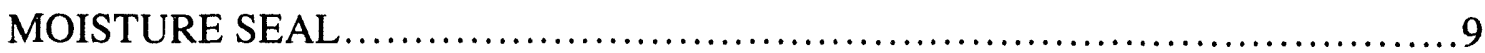

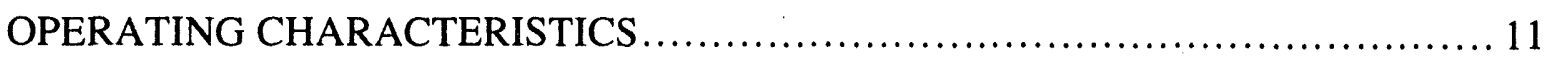

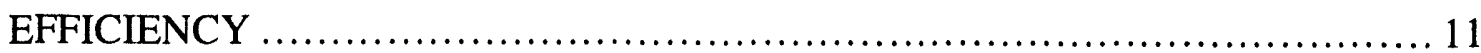

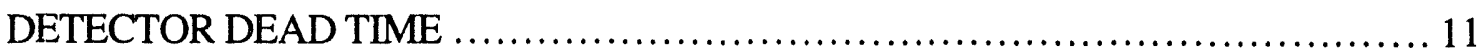

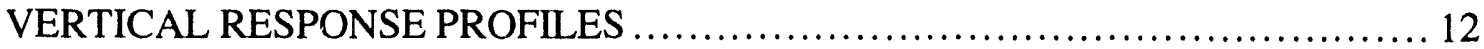

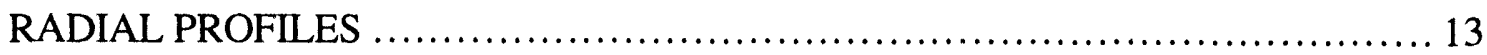

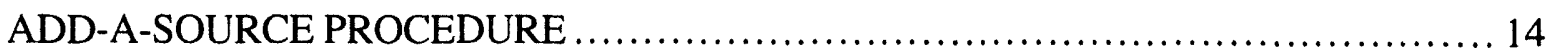

ADD-A SOURCE METHOD .............................................. 14

ADD-A-SOURCE CALIBRATION ........................................ 16

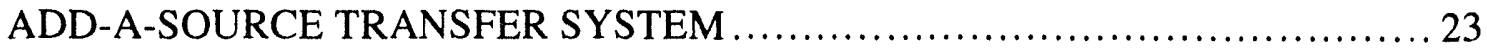




\section{CONTENTS (cont.)}

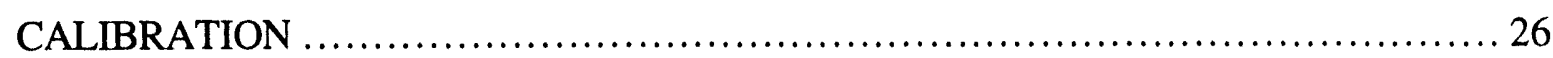

MATRIX STUDY RESULTS .................................................. 26

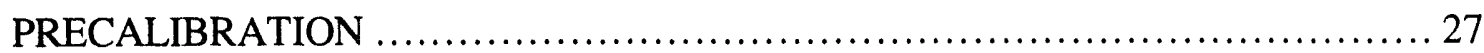

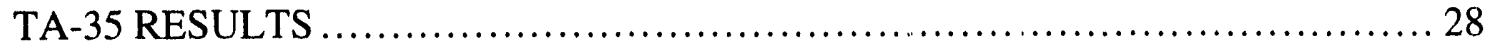

TA-55 CALIBRATIONS ..................................................... 30

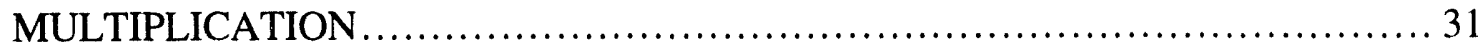

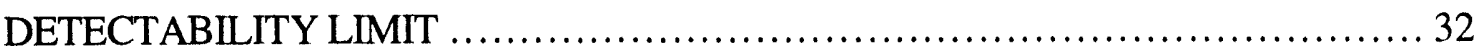

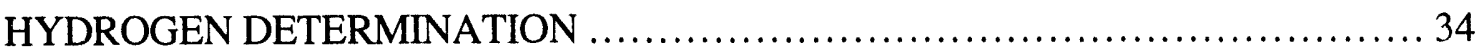

NORMALIZATION PROCEDURE ................................................. 35

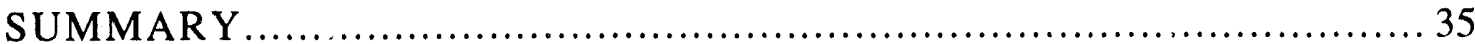

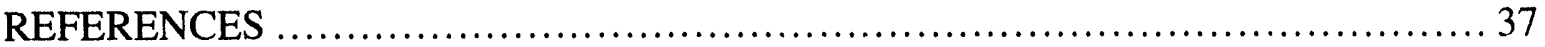




\title{
NBC OPERATION MANUAL INCLUDING THE MULTI-POSITION ADD-A-SOURCE FUNCTION
}

\author{
by
}

H. O. Menlove, L. A. Foster, and J. Baca

\begin{abstract}
This manual describes the design modifications and operating characteristics of a $200-\ell$-drum neutron coincidence counter. The counter has six shielded banks of ${ }^{3} \mathrm{He}$ tubes and JSR-11 shift register coincidence electronics. The modified design has a counting efficiency of $19.3 \%$. The neutron counter measures the spontaneousfission rate from the plutonium, and when this is combined with the plutonium isotopic ratios, we can determine the plutonium mass. The system includes the new multi-position add-a-source (AS) technique that uses a small ${ }^{252} \mathrm{Cf}$ source to determine the drum's matrix perturbation to the plutonium assay. The ${ }^{252} \mathrm{Cf}$ source is measured at three positions on the exterior of the drum to obtain the spatial distribution for the matrix correction. This manual gives the performance and calibration parameters. The matrix corrections by the AS technique are accurate to a few percent for typical applications.
\end{abstract}


GENERAL

PHYSICAL DESCRIPTION
This manual describes the design modifications and operating characteristics of the Neutron Barrel Counter (NBC). This drum counter will be used at TA-55 to determine the plutonium content of $200-\ell$ drums.

Los Alamos prepared the specifications and conceptual design of the drum counter. ${ }^{1}$ Jomar Systems/Canberra designed and built the counter. After fabrication, the counter was delivered to the Los Alamos National Laboratory for a program of performance measurements and acceptance testing, add-a-source (AS) installation, ${ }^{2}$ initial calibration, software installation and checkout, and preparation of documentation. This manual describes the measured drum counter performance characteristics and the instrument settings required for operation and constitutes part of the documentation for the counter.

The system includes the following hardware:

- detector head,

- Compumotor drive system for AS,

- ${ }^{252} \mathrm{Cf}$ source for the AS and normalization measurements,

- electronics rack,

- JSR-11 coincidence counting electronics,

- personal computer, and

- printer.

Figure 1 shows a photograph of the drum counter with the door open. The interior well is 711 by 711 by $965 \mathrm{~mm}$ high and can easily hold a standard $200-\ell$ drum, which can be loaded by rolling it along the fixed platform of rotating wheels as shown in the figure. The door is moved back and forth on its wheels by a motor positioned on top of the counter.

The counter has six banks of ${ }^{3} \mathrm{He}$ tubes-one in each of the four sides and one on the top and bottom. The four vertical side banks each contain ten $914-\mathrm{mm}$-active-length ${ }^{3} \mathrm{He}$ tubes, and the top and bottom horizontal banks each contain ten 508-mm-active-length ${ }^{3} \mathrm{He}$ tubes. The four vertical side banks each require two AMPTEK counting channels consisting of AMPTEK Model A-111 preamp/discriminator 


\section{PHYSICAL DESCRIPTION}

(cont.)

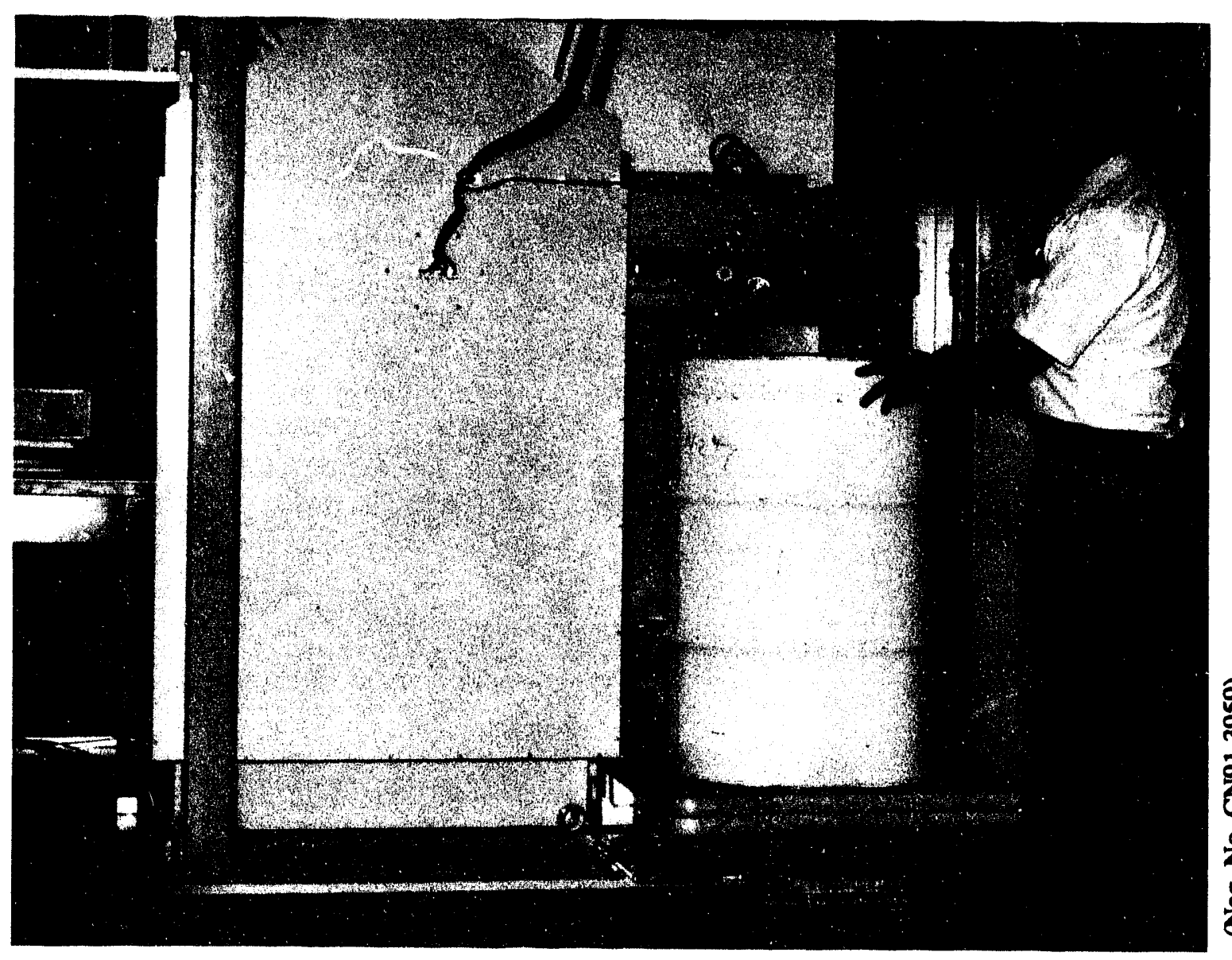

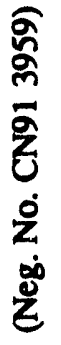

Fig. 1. Photograph of neutron detector showing the open sample cavity and a 200- $\ell$ drum. 
PHYSICAL DESCRIPTION (cont.) boards. The two horizontal banks use shorter ${ }^{3} \mathrm{He}$ tubes with less capacitance and each requires only one AMPTEK counting channel. The electronics of the NBC are similar to those of the HLNC-II. ${ }^{3,4}$ The detector counts the totals and coincidence neutrons from the spontaneous fission of the even isotopes of plutonium.

On one side of the counter is a panel with 10 numbered lights, each corresponding to one of the 10 AMPTEK channels. Table I lists the 10 channel numbers and the corresponding location of the AMPTEKs inside the counter. Table II gives the characteristics of the ${ }^{3} \mathrm{He}$ tubes.

Each of the six banks of ${ }^{3} \mathrm{He}$ tubes is embedded in a 100 -mm-thick slab of high-density polyethylene $\left(\mathrm{CH}_{2}\right)$. Each bank is also shielded on the outside by another 100 -mm-thick slab of $\mathrm{CH}_{2}$. Within the six detector banks, the ${ }^{3} \mathrm{He}$ tubes are centered $4.16 \mathrm{~cm}$ from the inside edge of the $\mathrm{CH}_{2}$.

\begin{tabular}{|c|l|}
\hline \multicolumn{2}{|l|}{ Table I. AMPTEK Channel Location } \\
\hline Channel No. & \multicolumn{1}{c|}{ Position } \\
\hline 1 & Bottom bank \\
\hline 2 & Right bank front end \\
\hline 3 & Right bank back end \\
\hline 4 & Back bank right end \\
\hline 5 & Back bank left end \\
\hline 6 & Top bank \\
\hline 7 & Door bank right end \\
\hline 8 & Door bank left end \\
\hline 9 & Left bank back end \\
\hline 10 & Left bank front end \\
\hline
\end{tabular}


PHYSICAL DESCRIPTION (cont.)

DOOR OPERATION

COMPUTER HARDWARE

\begin{tabular}{|l|l|}
\hline \multicolumn{2}{|l|}{ Table II. Characteristics of ${ }^{3} \mathrm{He}$ Tubes } \\
\hline Model (sides) & RS-P4-0836-203 \\
\hline Model (top \& bottom) & RS-P4-0820-203 \\
\hline Active length & $914 \mathrm{~mm}$ vertical \\
\hline & $508 \mathrm{~mm}$ horizontal \\
\hline Diameter & $25 \mathrm{~mm}$ \\
\hline Fill pressure & 4 atm \\
\hline Gas quench & Argon $+\mathrm{CH}_{4}$ \\
\hline Cladding & Stainless steel \\
\hline Operating high voltage & $1660 \mathrm{~V}$ \\
\hline \hline
\end{tabular}

The cadmium liners that Jomar Systems/Canberra normally places on the sample cavity walls and also between the detector slabs and the exterior $\mathrm{CH}_{2}$ shield were removed for the NBC modifications. The liners were removed to increase the detector's efficiency and to decrease the coincidence neutron background. The cadmium increases the coincidence background from cosmic-ray spallation reactions and its removal improves the sensitivity of the system for lowbackground applications.

Figure 2 shows the front panel of the control box that the operator uses to open and close the door. To activate the door, the operator must hold down the "DOOR ENABLE" button as well as either the "OPEN DOOR" or "CLOSE DOOR" button. Once the door has reached its opening or closing limit, it will trigger the limit sensor, the appropriate "LIMIT" light on the control box will turn on, and the door will automatically stop. Just beyond the opening limit sensor is a second sensor that will stop the door in the event that the first fails to do so. In that situation, the "EMERGENCY LIMIT" light on the control box will turn on. Once the door has reached its limit, it can be moved only in the opposite direction.

System interconnections between the computer, the JSR-11, the control box, and the drum counter are illustrated in Fig. 3. 
PHYSICAL DESCRIPTION

(cont.)

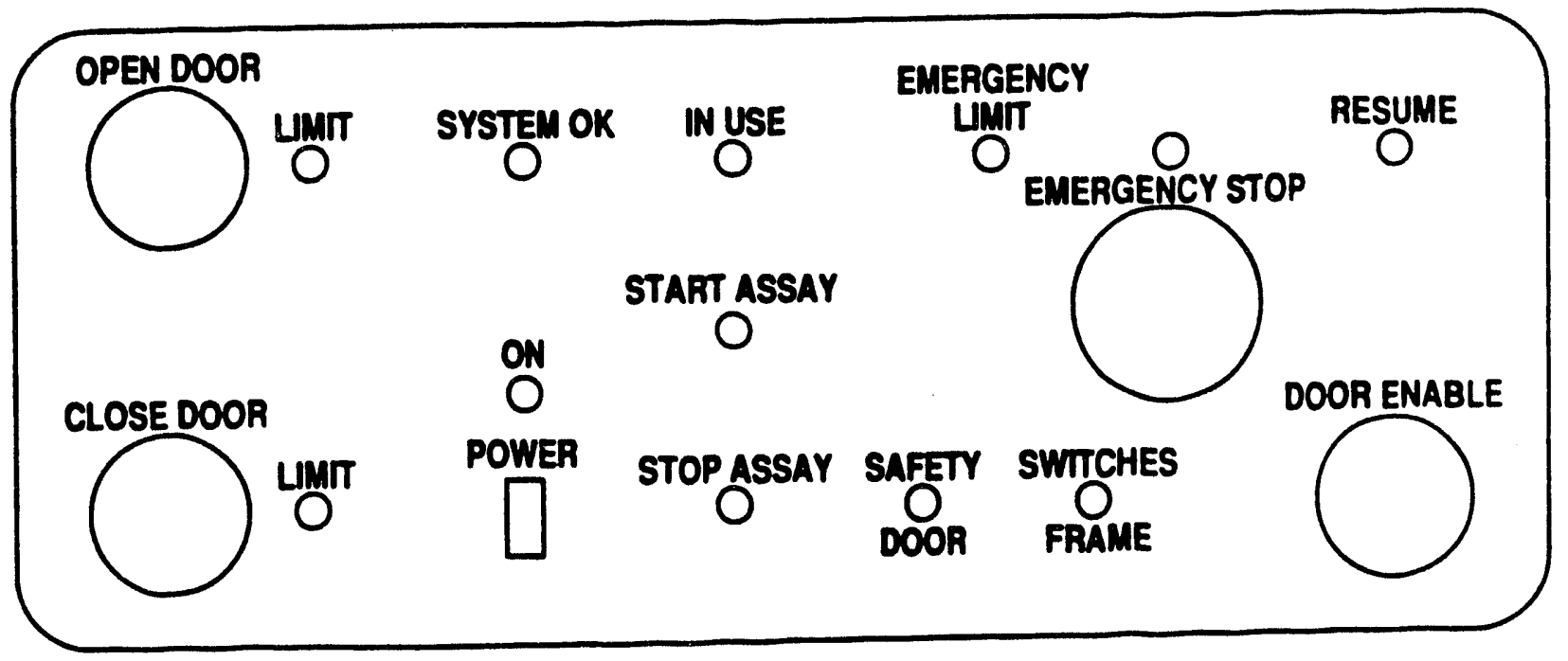

Fig. 2. Schematic diagram of the NBC door controller face panel.

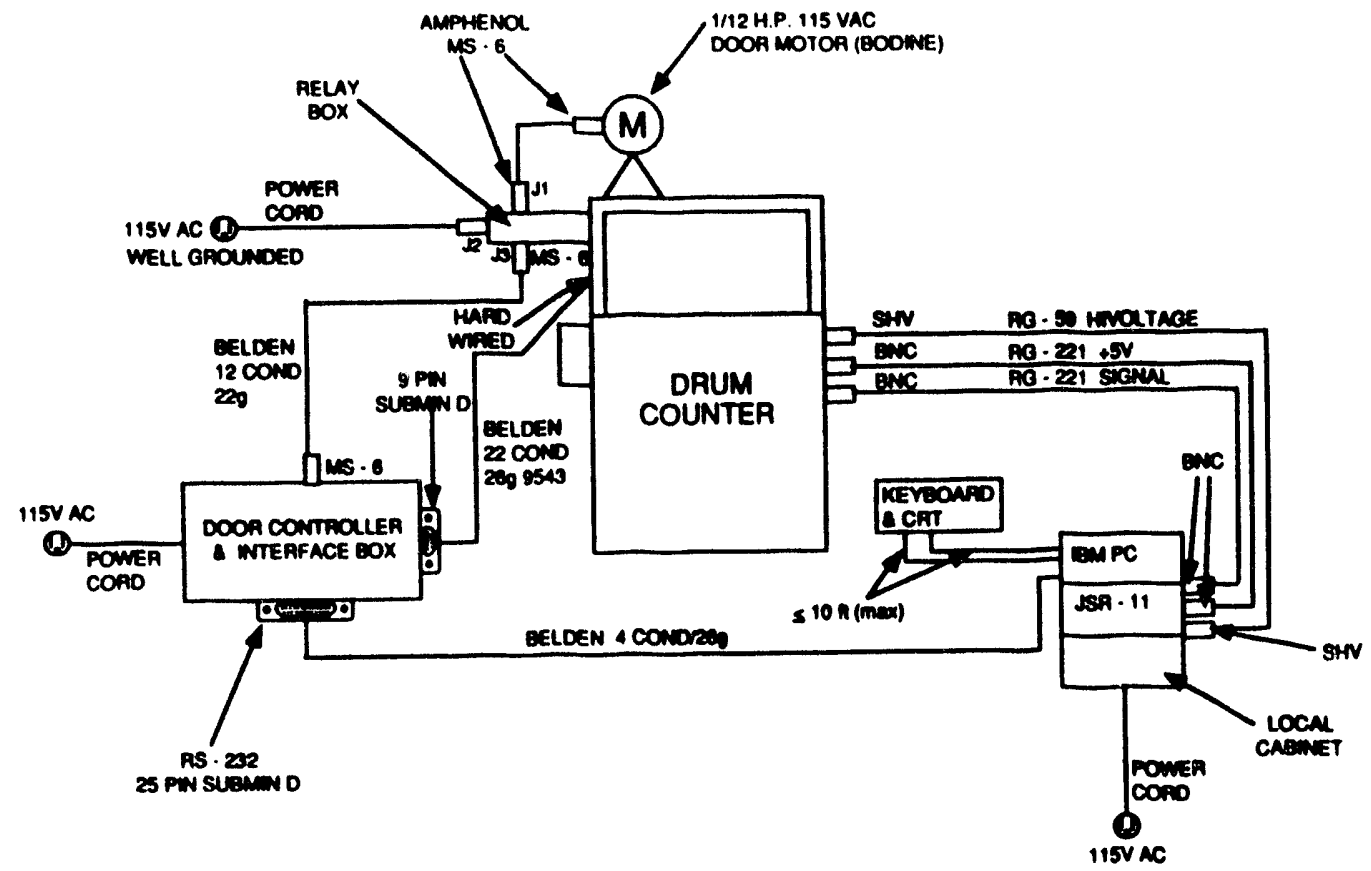

Fig. 3. Wiring diagram for the NBC door motor and controller. 
CALIBRATION SOURCE

System Check
A ${ }^{252} \mathrm{Cf}$ reference source was assigned to the NBC system. This source was counted at the time of calibration and during subsequent use of the detector for normalization. The source, with an initial emission rate of $2.5 \times 10^{4} \mathrm{n} / \mathrm{s}$, is adequate for at least 10 years in the NBC.

For convenience, the same source is used for both the normalization and the AS function. The normalization measurement is made with an empty chamber. 
ANALOG ELECTRONICS

high-VOLTAGE PLATEAU

MOISTURE SEAL
The NBC uses the fast-counting circuitry ${ }^{4}$ based on the miniature AMPTEK hybrid chip. These chips are located near the end of the ${ }^{3} \mathrm{He}$ tubes (see Fig. 4) and contain the preamplifier, amplifier, and discriminator circuits. Ten of these amplifier units are located in the top part of the six detector banks. The output signals from these 10 amplifiers are added and sent to the input of the shift-register board. The connection is made through the "external SR input" on the back panel of the JSR-11 shift-register.*

The high-voltage (hv) plateau for the $\mathrm{NBC}{ }^{3} \mathrm{He}$ tubes is shown in Fig. 5 where the totals counting rate is plotted as a function of the hv bias on the detector tubes. The "knee" or start of the plateau is at $1630 \mathrm{~V}$, and we set the operating voltage at $1660 \mathrm{~V}$. A higher setting can result in a coincidence bias at high counting rates and increased gamma-ray sensitivity at high dose levels. The setting at $1660 \mathrm{~V}$ is not sensitive to gamma rays for dose levels up to $\sim 1 \mathrm{R} / \mathrm{h}$ at the surface of the drums.

To avoid moisture buildup in the hv junction box of the detector, the box contains desiccant and the openings are sealed with silicone rubber. The humidity and degree of r.1oisture saturation in the desiccant can be read from outside the junction box. Also, the desiccant tubes can be exchanged for fresh tubes.

*Model JSR-11, JOMAR Systems, Los Alamos, NM 87544. 


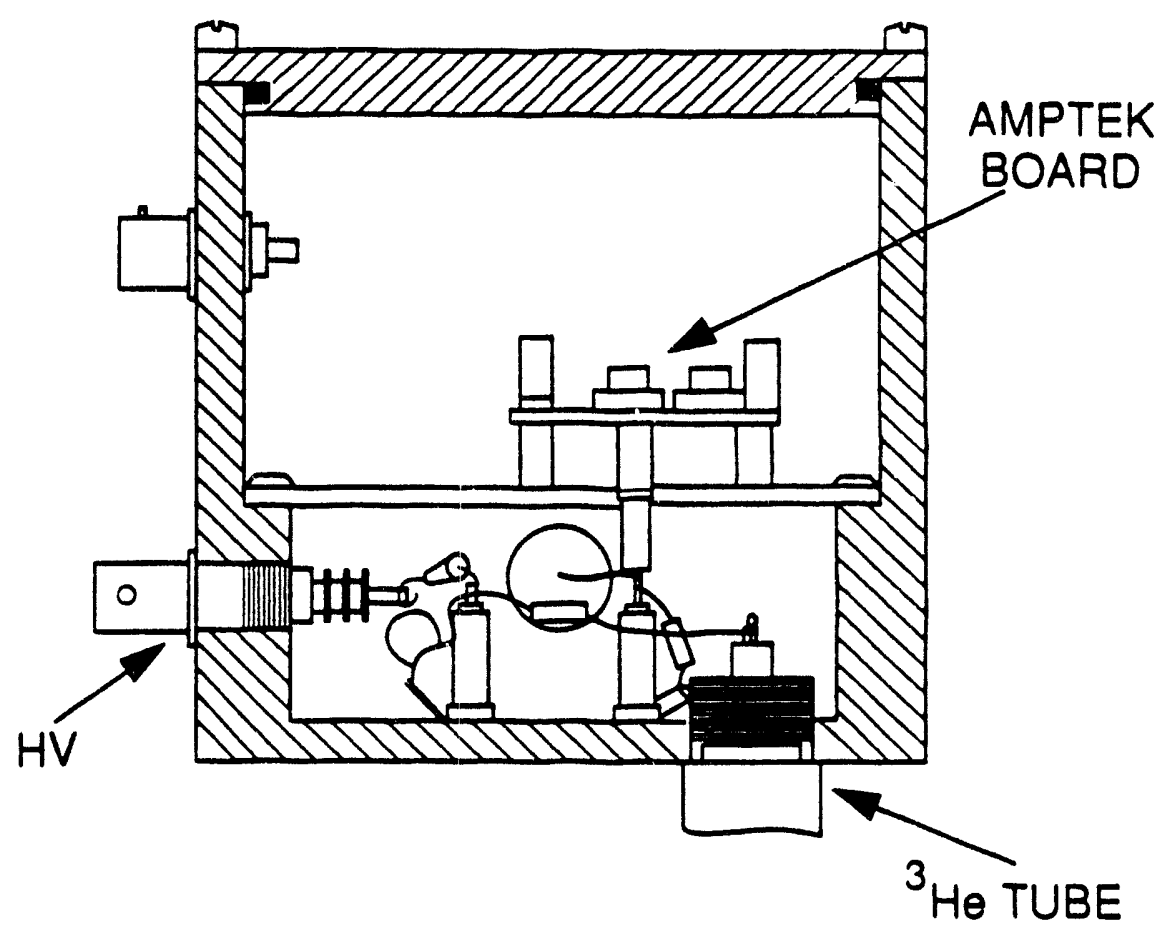

Fig. 4. Diagram of the hv junction box that contains the AMPTEK board.

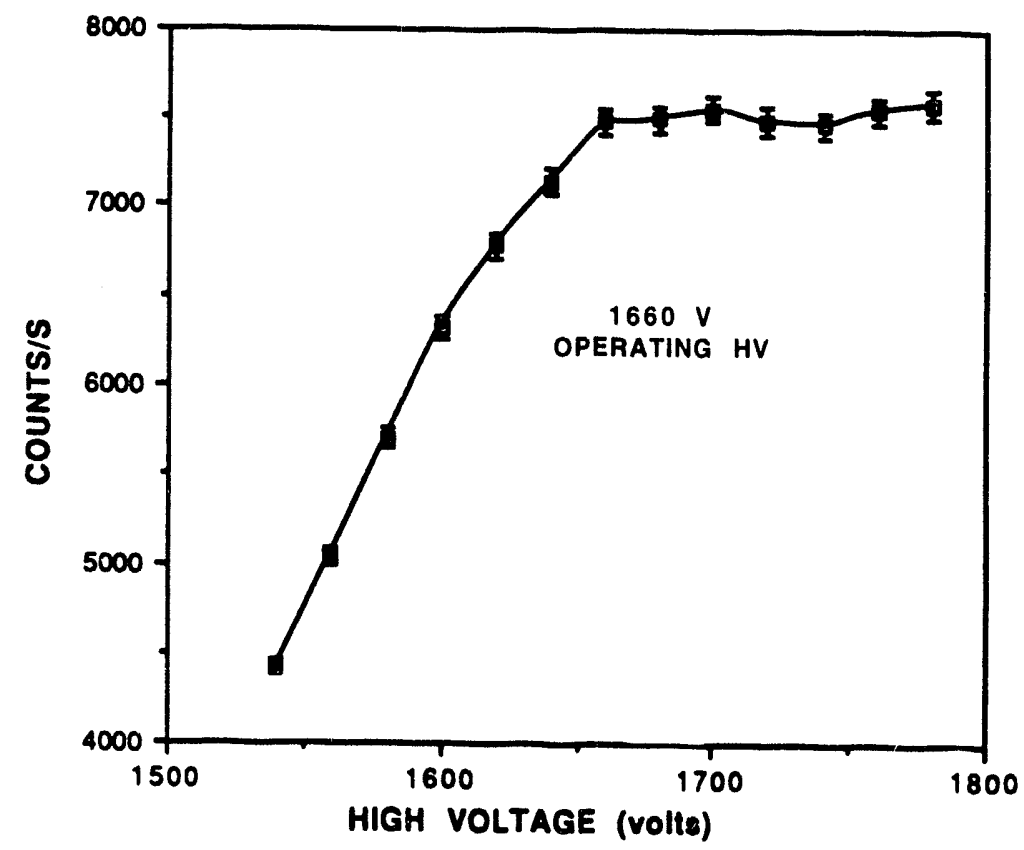

Fig. 5. Totals counting rate vs the hv setting of the ${ }^{3}$ He tubes in the NBC. 
EFFICIENCY

DETECTOR DEADTIME
The efficiency of the NBC system was measured using a calibrated ${ }^{252} \mathrm{Cf}$ source in the detector. The results are listed in Table III.

\begin{tabular}{|l|c|}
\hline \multicolumn{2}{|c|}{ Table III. NBC Performance Characteristics } \\
(date: 93-03-25)
\end{tabular}

We used a ${ }^{252} \mathrm{Cf}$ source to measure a die-away time of $79 \mu \mathrm{s}$.

The NBC uses the same basic electronics and amplifiers as does the HLNC-II. The dead time coefficient $\delta$ is given by

$\delta=\left(a+b T \times 10^{-6}\right) \mu \mathrm{s}$,

where $T$ is the measured totals rate in counts/s and $a$ and $b$ are constants given in Table III. The corrected counting rates are

$T($ corr. $)=T \mathrm{e}^{\delta T / 4}$

and

$R($ corr. $)=R \mathrm{e}^{\delta T}$ 


\section{DETECTOR DEADTIME}

(cont.)
It is important to use the same dead-time coefficient for both calibration and assay so that any errors in the correction will cancel to a first approximation.

At very high counting rates ( $T \geq 1 \mathrm{MHz}$ ), a small positive bias appears in the dead-time corrected rates.

Our counting rates are expected to be less than $1 \mathrm{MHz}$, so we shall use the standard $4.5-\mu$ s predelay setting.

To determine sample positioning effects, we counted a ${ }^{252} \mathrm{Cf}$ point source at a variety of vertical and radial positions in an empty drum. The measurements were made using the (WDAS) detector ${ }^{2}$ that has the same geometry as the NBC. The vertical profile measurements were made at a radius of $20 \mathrm{~cm}$ from the center of the $200-\ell$ drum. The outside edge of the drum has a radius of $28 \mathrm{~cm}$ and the $20-\mathrm{cm}$ radius is approximately the volume-averaged mean radius. That is, the drum volume inside $20 \mathrm{~cm}$ equals the volume outside $20 \mathrm{~cm}$.

Figure 6 shows the normalized vertical totals and reals rates for the ${ }^{252} \mathrm{Cf}$ source. The dips at the top and bottom are caused by the gaps in the detector coverage at the ends of the detector banks.

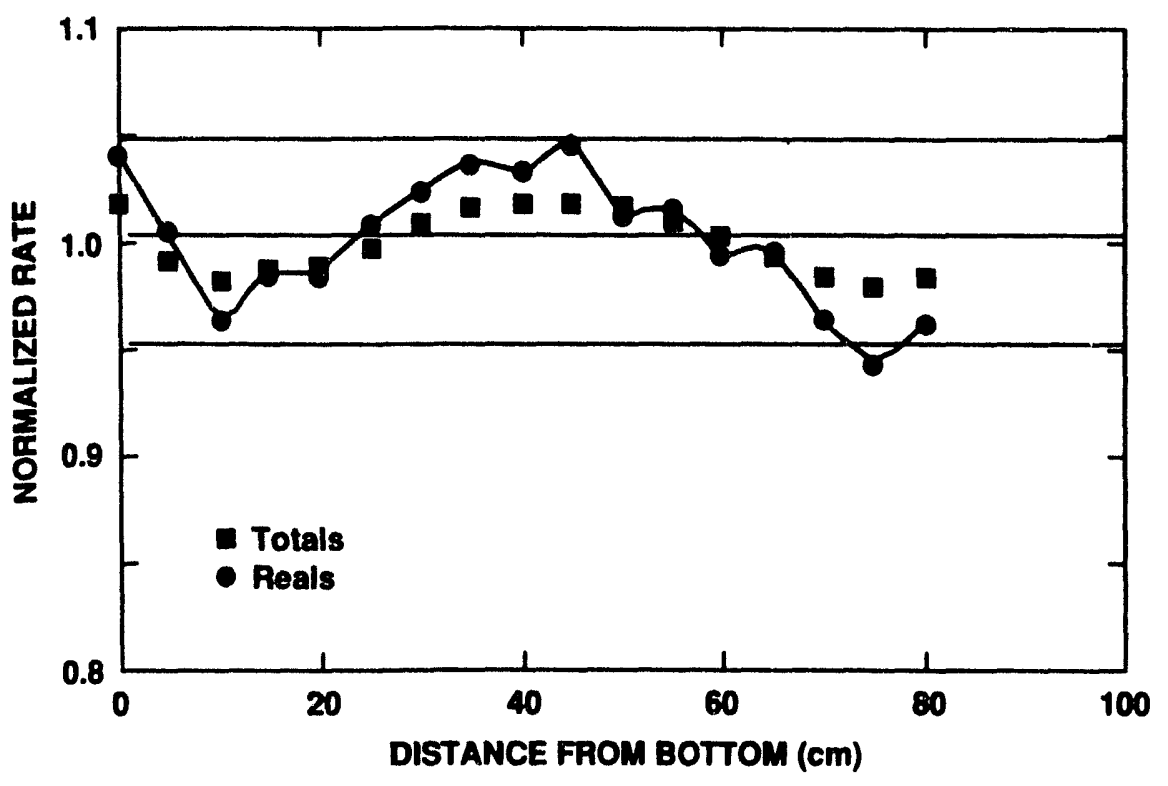

Fig. 6. Totals and reals vertical response profiles measured using ${ }^{252} \mathrm{Cf}$ at a radius of $20 \mathrm{~cm}$ in an empty $200-\ell$ drum. 
RADIAL PROFILES For the radial profile, the ${ }^{252} \mathrm{Cf}$ source was positioned at four different radial positions and three different vertical positions. Figure 7 shows the radial profile for the average of the three vertical positions. The vertical positions were 15,35 , and $55 \mathrm{~cm}$ above the bottom of the drum.

The multiplication-corrected reals profiles are not given because, for the waste drums, the multiplication-corrected rates are not used. This is because the multiplication is negligible and normally the $\alpha$ parameter is unknown.

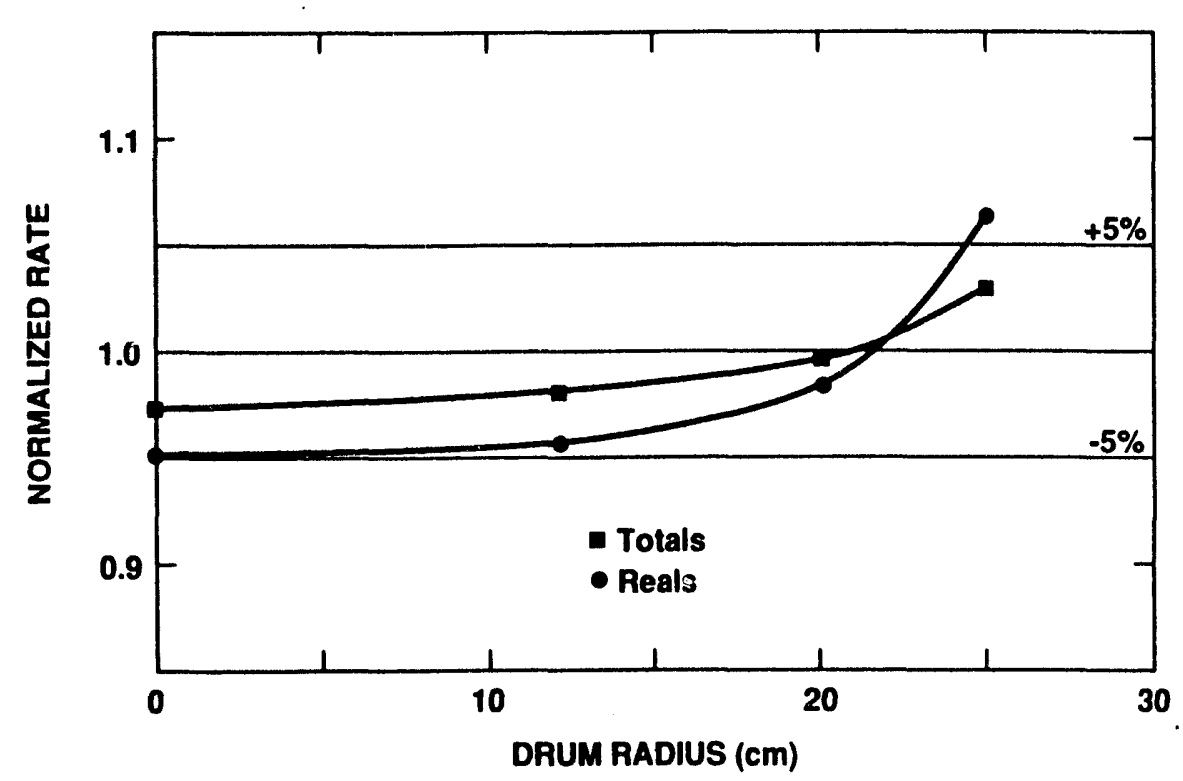

Fig. 7. Totals and reals radial response profiles averaged over the heights of 15 , 35 , and $55 \mathrm{~cm}$ in an empty $200-\ell$ drum. 
ADD-A-SOURCE METHOD
The basis of the AS method is to measure the matrix perturbation to the counting rate from a small ${ }^{252} \mathrm{Cf}$ source $(2.5 \mathrm{x}$ $10^{4} \mathrm{n} / \mathrm{s}$ ) on the outside of the sample and to use the information to correct for the matrix perturbation on the inside of the sample. For the present case, we have positioned the AS neutron source at three positions on the $200-\ell$ drum.

Figure 8 shows a schematic diagram that illustrates the technique in which the AS neutrons originate from ${ }^{252} \mathrm{Cf}$ and the sample neutrons originate from plutonium. The figure shows the location of the three positions on the bottom and side of the drum.

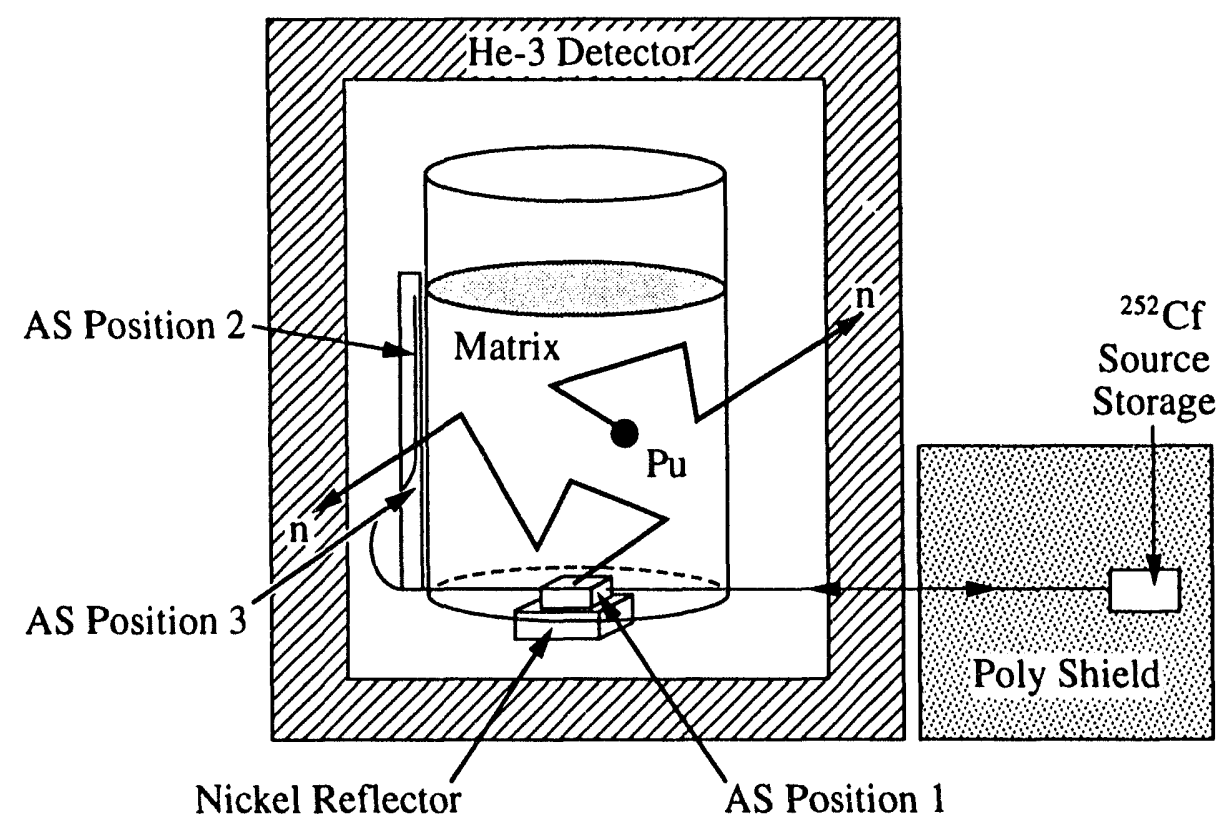

Fig. 8. Schematic illustration for the AS concept showing the Teleflex cable transfer system that moves the ${ }^{252} \mathrm{Cf}$ source from the shielded storage position to the matrix interrogation position.

The sample matrix has two primary effects on the neutrons: (1) energy reduction by scattering reactions, and (2) neutron absorption of the low-energy neutrons. The counter is designed with an optimum moderator $\left(\mathrm{CH}_{2}\right)$ thickness to be relatively insensitive to the energy reduction; however, as the hydrogen density in the drum increases, the absorption process significantly reduces the measured neutron signal. 


\section{ADD-A-SOURCE METHOD}

(cont.)

To correct for the matrix perturbation on the neutron signal, the AS method measures each drum both with and without the ${ }^{252} \mathrm{Cf}$ source on the outside of the drum. The measured quantities are

$$
\begin{array}{ll}
T_{0}, R_{0} & =\begin{array}{l}
\text { Totals and reals rates from }{ }^{252} \mathrm{Cf} \text { for } \\
\text { an empty drum. }
\end{array} \\
T, R & \begin{array}{l}
\text { Totals and reals rates from a sample drum } \\
\text { without }{ }^{252} \mathrm{Cf} .
\end{array} \\
T(\mathrm{Cf}), R(\mathrm{Cf})= & \begin{array}{l}
\text { Totals and reals rates from a sample drum } \\
\text { with the }{ }^{252} \mathrm{Cf} .
\end{array}
\end{array}
$$

The net ${ }^{252} \mathrm{Cf}$ reals rate for the ${ }^{252} \mathrm{Cf}$ and a loaded sample drum is

$R(\mathrm{Cf})-R=R($ net $)$

We use the ratio of the empty drum (after source decay correction) to the net loaded drum to make the matrix correction as follows:

$\left(\frac{R_{0} \mathrm{e}^{-\lambda t}}{R(\mathrm{net})}-1\right)=x$,

and the correction factor $(C F)$ is defined as

$C F=1+f(x)$

where $f(x)$ is a polynomial function of $x$ based on empirical measurements. The measured $R$ for a drum is corrected to give

$R($ corrected $)=R($ measured $) C F$.

ADD-A-SOURCE

CALIBRATION
The functional relationship between the AS perturbation $x$ and the volume averaged sample perturbation $f(x)$ was determined empirically by measuring a large variety of matrix loadings with the AS. The matrix materials in the drums are listed in Table IV. 


\section{ADD-A-SOURCE \\ CALIBRATION \\ (cont.)}

Table IV. Matrix Materials

\begin{tabular}{|l|c|c|}
\hline \multicolumn{1}{|c|}{ Matrix } & Matrix Weight $(\mathrm{kg})$ & $\rho_{\mathrm{H}}\left(\mathrm{g} / \mathrm{cm}^{3}\right)$ \\
\hline Empty (19.3 kg steel drum) & 0.0 & 0.0 \\
\hline Vermiculite + Borax & 34.0 & 0.0008 \\
\hline Paper & 20.9 & 0.007 \\
\hline Boron Glass & 142.0 & 0 \\
\hline Polyethylene Shavings & 11.8 & 0.0086 \\
\hline Polyethylene Tubes & 42.6 & 0.031 \\
\hline Wood & 54.6 & unknown \\
\hline \multirow{2}{*}{$\begin{array}{c}\text { Vermiculite + } \\
29.5 \text { kg of Poly Beads }\end{array}$} & 40.0 & 0.0212 \\
\hline \multirow{2}{*}{$\begin{array}{c}\text { Vermiculite + } \\
59.1 \text { kg of Poly Beads }\end{array}$} & 78.5 & 0.0423 \\
\hline \multirow{2}{*}{$\begin{array}{c}\text { Concrete (top) + } \\
\text { Poly Shavings (bottom) }\end{array}$} & 100 & unknown \\
\hline Concrete (bottom) + Paper (top) & & unknown \\
\hline \hline
\end{tabular}

A separate neutron source was counted at nine positions in the drum to give a volume averaged matrix effect. The nine positions are illustrated in Fig. 9. The average of the nine positions was then ratioed to the empty drum case to give the volume averaged perturbation

$\left[\frac{\left.R_{0}^{\prime} \text { (empty vol }\right)}{R^{\prime} \text { (matrix vol) }}-1\right]=y($ vol av perturbation $)$,

where

$R_{0}^{\prime} \quad=$ reals rates averaged over the volume of an empty drum and

$R^{\prime}=$ reals rates averaged over the volume of the drum with matrix material. 
ADD-A-SOURCE

CALIBRATION

(cont.)

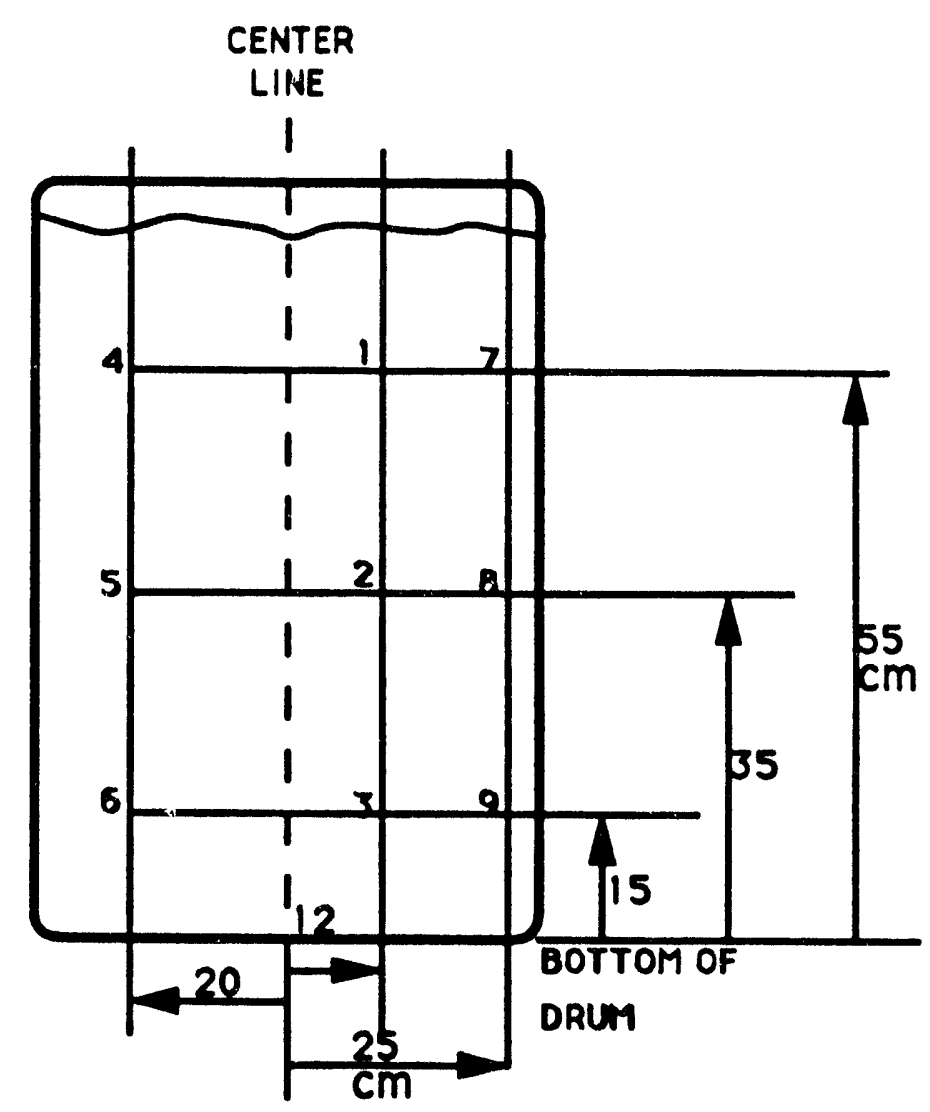

Fig. 9. Diagram of the neutron source positions to give a volume averaged response in a $200-\ell$ drum.

Table $\mathrm{V}$ list the totals and reals rates and errors for the volume averaged case for a few of the matrix materials. A typical drum contained $\sim 190 \ell$ of matrix material.

Table VI gives the AS reals data for the three positions (see Fig. 9) on the drum. The ratio of each count to the average of the three positions can be used to flag discontinuities in the matrix loading. Position 1 (bottom of drum) picks up the hydrogen increase in the matrix with more sensitivity than positions 2 and 3 (side positions) because of the better geometric coupling to the bottom of the drum. 


\section{ADD-A-SOURCE}

CALIBRATION

(cont.)
The AS correction factor is derived from the volume averaged reals ratio for the empty drum over the matrix filled drum compared with the corresponding AS reals ratio. This data is given in Table VII.

A plot of the volume averaged perturbations $y$ vs the AS perturbation $x$ is shown in Fig. 10. The data point with the highest AS perturbation corresponds to a drum loaded with $\mathrm{CH}_{2}$ beads and vermiculite $\left(\rho=\rho_{\mathrm{H}}=0.0423 \mathrm{~g} / \mathrm{cm}^{3}\right)$. The hydrogen content in this drum is equivalent to $38 \%$ of the hydrogen content of water.

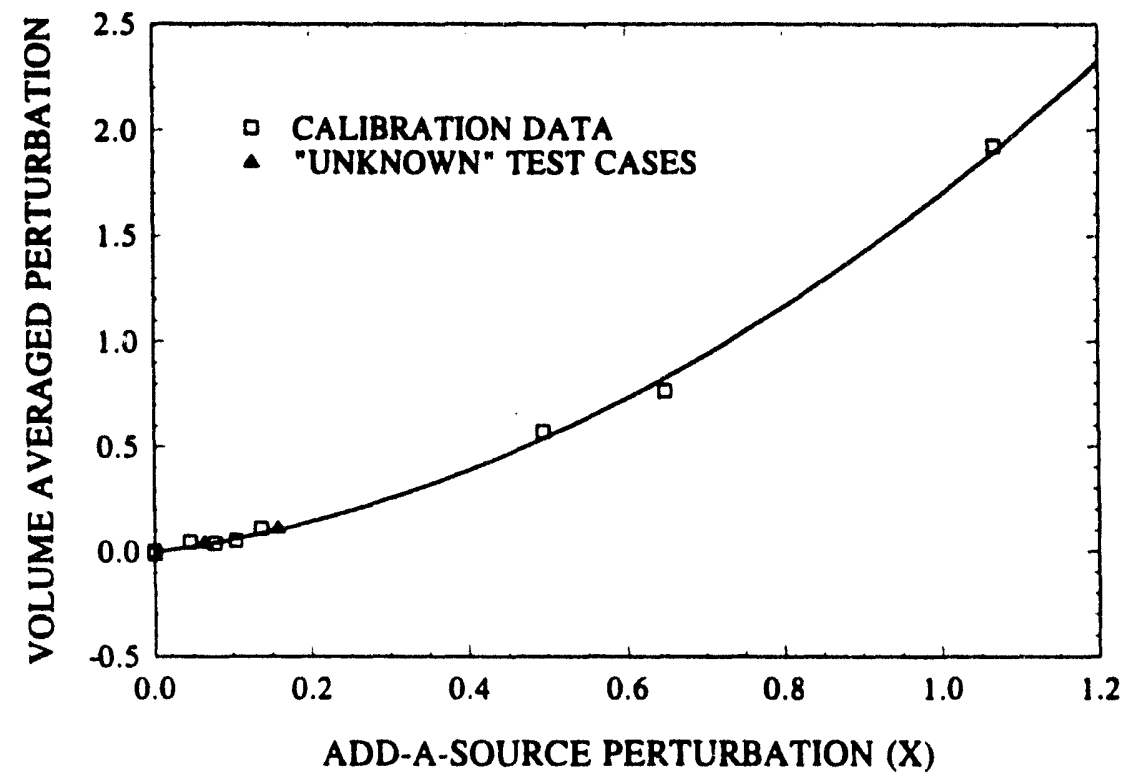

Fig. 10. The AS perturbation $(x)$ in $R$ vs the volume averaged perturbation (y) in $R^{\prime}$ for a variety of matrix materials in $200-\ell$ drums. 


\section{ADD-A-SOURCE \\ CALIBRATION}

(cont.)

\begin{tabular}{|c|c|c|c|c|c|c|}
\hline Sample & Position & $\begin{array}{l}\text { Meas } \\
\text { Time } \\
\text { (s) }\end{array}$ & $\begin{array}{l}\text { Reals } \\
(1 / s)\end{array}$ & $\begin{array}{l}\text { Sigma } \\
\text { Reals }\end{array}$ & $\begin{array}{l}\text { Totals } \\
(1 / s)\end{array}$ & $\begin{array}{l}\text { Sigma } \\
\text { Totals }\end{array}$ \\
\hline \multirow[t]{6}{*}{$2 / 24 / 93$} & $\begin{array}{l}T \\
2\end{array}$ & $\begin{array}{l}480 \\
420\end{array}$ & $\begin{array}{l}79.9 \\
82.3\end{array}$ & $\begin{array}{l}0.47 \\
0.47\end{array}$ & $\begin{array}{l}483.1 \\
490.1\end{array}$ & $\begin{array}{l}0.94 \\
0.91\end{array}$ \\
\hline & $\begin{array}{l}3 \\
4 \\
\end{array}$ & $\begin{array}{l}450 \\
450 \\
\end{array}$ & $\begin{array}{l}76.5 \\
84.2\end{array}$ & $\begin{array}{l}0.54 \\
0.73\end{array}$ & $\begin{array}{l}473.4 \\
493.7\end{array}$ & $\begin{array}{l}1.64 \\
1.28\end{array}$ \\
\hline & $\begin{array}{l}5 \\
6\end{array}$ & $\begin{array}{l}540 \\
480 \\
\end{array}$ & $\begin{array}{l}85.1 \\
81.2 \\
\end{array}$ & $\begin{array}{l}0.59 \\
0.78\end{array}$ & $\begin{array}{l}500.6 \\
487.7\end{array}$ & $\begin{array}{l}T .11 \\
1.16\end{array}$ \\
\hline & $\begin{array}{l}7 \\
8\end{array}$ & $\begin{array}{l}480 \\
480\end{array}$ & $\begin{array}{l}82.3 \\
84.2\end{array}$ & $\begin{array}{l}0.73 \\
0.66\end{array}$ & $\begin{array}{l}491.5 \\
495.5\end{array}$ & $\begin{array}{l}T .27 \\
1.64\end{array}$ \\
\hline & 9 & 420 & 75.6 & 0.56 & 470.8 & 0.73 \\
\hline & Av & $\cdots$ & 81.3 & 0.21 & 487.4 & 0.41 \\
\hline \multirow{7}{*}{$\begin{array}{l}\text { Boron Glass } \\
3 / 2 / 93\end{array}$} & & & & & & \\
\hline & $\begin{array}{l}1 \\
2\end{array}$ & $\begin{array}{l}420 \\
420\end{array}$ & $\begin{array}{l}73.0 \\
81.5\end{array}$ & $\begin{array}{l}0.41 \\
0.54\end{array}$ & $\begin{array}{l}434.2 \\
456.5\end{array}$ & $\begin{array}{l}1.15 \\
1.10\end{array}$ \\
\hline & $\begin{array}{l}3 \\
4 \\
\end{array}$ & $\begin{array}{l}450 \\
420\end{array}$ & $\begin{array}{l}79.1 \\
74.0\end{array}$ & $\begin{array}{l}0.39 \\
0.95\end{array}$ & $\begin{array}{l}448.4 \\
437.3\end{array}$ & $\begin{array}{l}1.03 \\
1.18\end{array}$ \\
\hline & $\begin{array}{l}5 \\
6 \\
\end{array}$ & $\begin{array}{l}420 \\
420\end{array}$ & $\begin{array}{l}82.4 \\
74.7\end{array}$ & $\begin{array}{l}0.71 \\
0.87\end{array}$ & $\begin{array}{l}456.9 \\
439.2\end{array}$ & $\begin{array}{l}1.09 \\
2.05\end{array}$ \\
\hline & $\begin{array}{l}7 \\
8\end{array}$ & $\begin{array}{l}420 \\
450\end{array}$ & $\begin{array}{l}75.4 \\
83.2\end{array}$ & $\begin{array}{l}0.92 \\
1.04\end{array}$ & $\begin{array}{l}438.4 \\
456.9\end{array}$ & $\begin{array}{l}0.86 \\
1.45\end{array}$ \\
\hline & 9 & 420 & 71.9 & 0.60 & 425.8 & 0.85 \\
\hline & Av & $\cdots$ & 77.2 & 0.25 & 443.7 & 0.41 \\
\hline \multirow{10}{*}{$\begin{array}{l}\text { Poly Shavings } \\
2 / 25 / 93\end{array}$} & & & & & & \\
\hline & $\begin{array}{l}1 \\
2\end{array}$ & $\begin{array}{l}420 \\
450\end{array}$ & $\begin{array}{l}77.3 \\
76.2\end{array}$ & $\begin{array}{l}0.71 \\
0.59\end{array}$ & $\begin{array}{l}482.3 \\
487.5\end{array}$ & $\begin{array}{l}1.10 \\
1.73\end{array}$ \\
\hline & 3 & 450 & 71.8 & 0.58 & 469.6 & T.3 \\
\hline & 4 & 450 & 81.4 & 0.69 & 495.3 & 1.50 \\
\hline & 5 & 420 & 82.2 & 0.73 & 500.7 & 1.50 \\
\hline & 6 & 450 & 78.2 & 0.86 & 484.9 & 0.96 \\
\hline & 7 & 420 & 78.4 & 0.76 & 484.5 & 1.35 \\
\hline & 3 & 480 & 80.4 & 0.59 & 491.1 & 0.96 \\
\hline & 9 & 480 & 70.1 & 0.81 & 465.1 & 1.12 \\
\hline & Av & $\cdots$ & 77.3 & 0.24 & 484.6 & 0.43 \\
\hline \multirow{10}{*}{$\begin{array}{l}\text { Vermiculite + Poly Beads } 59.1 \mathrm{~kg} \\
3 / 30 / 93\end{array}$} & 1 & 450 & 20.1 & 0.64 & 282.1 & 151 \\
\hline & 2 & 420 & 13.4 & 0.58 & 241.4 & 1.53 \\
\hline & 3 & 420 & 16.4 & 0.63 & 255.8 & T.59 \\
\hline & 4 & 240 & 31.6 & 0.91 & 345.2 & 1.90 \\
\hline & 5 & 780 & 24.6 & 0.64 & 307.1 & 1.45 \\
\hline & 6 & 180 & 25.1 & 0.65 & 305.5 & 1.45 \\
\hline & $\begin{array}{l}7 \\
8 \\
\end{array}$ & $\begin{array}{l}180 \\
180 \\
\end{array}$ & $\begin{array}{l}41.3 \\
36.5 \\
\end{array}$ & $\begin{array}{l}0.84 \\
0.78 \\
\end{array}$ & $\begin{array}{l}372.0 \\
348.6 \\
\end{array}$ & $\begin{array}{l}1.64 \\
1.58\end{array}$ \\
\hline & 9 & 180 & 34.4 & $0 . \overline{75}$ & 337.0 & 1.55 \\
\hline & Av & $\cdots$ & 27.0 & 0.24 & 310.5 & 0.53 \\
\hline & & & & & & \\
\hline \multirow{9}{*}{$\begin{array}{l}\text { Concrete + Poly Shavings } \\
3 / 30 / 93\end{array}$} & $\mathrm{~T}$ & 120 & 67.5 & T.36 & 450.4 & 2.30 \\
\hline & 2 & 120 & 66.0 & 1.35 & 453.3 & 2.30 \\
\hline & 3 & 120 & 65.2 & T.32 & 445.8 & 2.28 \\
\hline & 4 & 120 & 78.5 & 1.48 & 481.4 & 2.40 \\
\hline & 5 & 720 & 80.0 & 7.50 & 482.2 & 2.41 \\
\hline & 6 & 120 & 73.5 & 1.42 & 462.9 & $\frac{2.35}{2.33}$ \\
\hline & $\begin{array}{l}7 \\
8\end{array}$ & $\begin{array}{l}120 \\
120\end{array}$ & $\begin{array}{l}72.1 \\
73.5\end{array}$ & $\begin{array}{l}1.41 \\
1.43\end{array}$ & $\begin{array}{l}457.5 \\
461.6\end{array}$ & $\begin{array}{l}2.33 \\
2.35\end{array}$ \\
\hline & 9 & 720 & 64.1 & 1.30 & 437.2 & 2.26 \\
\hline & $\overline{A v}$ & $\cdots$ & 71.2 & 0.47 & 459.1 & 0.78 \\
\hline
\end{tabular}


ADD-A-SOURCE

CALIBRATION

(cont.)

Table Vl. Add-a-Source Data as a Function of Position

\begin{tabular}{|c|c|c|c|c|}
\hline Sample & Position & Reals & Sigma R & Ratio to Av \\
\hline Empty Drum & 1 & 793.77 & 4.85 & 0.939 \\
\hline \multirow[t]{3}{*}{$2 / 24 / 93$} & 2 & 867.87 & 4.93 & 1.027 \\
\hline & 3 & 873.69 & 3.90 & 1.034 \\
\hline & Av & 845.11 & 2.65 & 1.000 \\
\hline Boron Glass & 1 & 686.40 & 3.99 & 0.878 \\
\hline \multirow{3}{*}{$3 / 2 / 93$} & 2 & 819.81 & 3.24 & 1.049 \\
\hline & 3 & 837.89 & 3.67 & 1.072 \\
\hline & Av & 781.36 & 2.11 & 1.000 \\
\hline Poly Shavings & 1 & 675.12 & 3.10 & 0.883 \\
\hline \multirow[t]{3}{*}{$2 / 25 / 93$} & 2 & 810.53 & 3.66 & 1.060 \\
\hline & 3 & 809.02 & 2.98 & 1.058 \\
\hline & $\mathrm{Av}$ & 764.89 & 1.88 & 1.000 \\
\hline Vermiculite + Poly Beads $59.1 \mathrm{~kg}$ & 1 & 341.34 & 4.26 & 0.855 \\
\hline \multirow[t]{3}{*}{$3 / 30 / 93$} & 2 & 454.03 & 5.12 & 1.137 \\
\hline & 3 & 402.08 & 4.82 & 1.007 \\
\hline & $\mathrm{Av}$ & 399.15 & 2.74 & 1.000 \\
\hline Concrete + Poly Shavings & 1 & 613.04 & 12.13 & 0.860 \\
\hline \multirow[t]{3}{*}{$3 / 30 / 93$} & 2 & 793.29 & 13.97 & 1.113 \\
\hline & 3 & 732.49 & 13.56 & 1.027 \\
\hline & $\mathrm{Av}$ & 712.94 & 7.65 & 1.000 \\
\hline
\end{tabular}




\section{ADD.A-SOURCE}

CALIBRATION

(cont.)

Table VII. ${ }^{252} \mathrm{Cf}$ Counting Rates for Add-a-Source and the Average over the Matrix Volume

\begin{tabular}{|l|l|l|l|l|l|l|}
\hline & \multicolumn{3}{|c|}{ Volume Average } & \multicolumn{3}{c|}{ Add-a-Source } \\
\hline & $T_{\mathrm{av}}$ & $R_{\mathrm{av}}$ & $T_{0} / T$ & $R_{0} / R$ & $R_{\mathrm{av}}$ & $R_{0} / R$ \\
\hline Empty Drum & 487.4 & 81.3 & 1.000 & 1.000 & 845.1 & 1.000 \\
\hline Vermiculite and Borax & 468.4 & 82.2 & 1.040 & 0.988 & 844.6 & 1.001 \\
\hline Paper-1 & 485.7 & 77.9 & 1.003 & 1.043 & 802.9 & 1.053 \\
\hline Paper-2 & 485.8 & 77.3 & 1.005 & 1.048 & 813.1 & 1.039 \\
\hline Wood & 479.4 & 73.2 & 1.018 & 1.107 & 744.0 & 1.136 \\
\hline Boron Glass & 450.1 & 78.3 & 1.083 & 1.037 & 784.7 & 1.077 \\
\hline Poly Shavings & 484.9 & 77.4 & 1.005 & 1.050 & 765.4 & 1.104 \\
\hline Poly Tubes & 404.4 & 46.1 & 1.205 & 1.763 & 512.6 & 1.649 \\
\hline Vermiculite + Poly Beads, 29.5 kg & 405.5 & 51.8 & 1.202 & 1.569 & 564.8 & 1.496 \\
\hline Vermiculite + Poly Beads, 59.1 kg & 318.2 & 27.7 & 1.535 & 2.924 & 408.9 & 2.067 \\
\hline Concrete + Poly Shavings & 470.5 & 72.9 & 1.038 & 1.112 & 730.4 & 1.157 \\
\hline Concrete + Paper & 481.3 & 78.0 & 1.014 & 1.039 & 794.2 & 1.064 \\
\hline \hline
\end{tabular}

A second order polynomial was fitted through the $y$ vs $x$ data using the Deming Code to give the predicted volume averaged matrix perturbation $f(x)$ based on the AS measured perturbation,

$y=f(x)=a_{0}+a_{1} x+a_{2} x^{2}$

where

$$
\begin{aligned}
& a_{0}=-0.004893 \pm 0.0105 \\
& a_{1}=0.5020 \pm 0.1152 \\
& a_{2}=1.200 \pm 0.1293
\end{aligned}
$$




\section{ADD-A-SOURCE \\ CALIBRATION}

(cont.)

ADD-A-SOURCE

TRANSFER SYSTEM with the variances and covariances as follows:

$\begin{array}{rrr}1 & 1 & 1.674 \mathrm{E}-2 \\ 1 & 2 & -1.410 \mathrm{E}-2 \\ 1 & 3 & 8.102 \mathrm{E}-4 \\ 2 & 2 & 1.327 \mathrm{E}-2 \\ 2 & 3 & -8.471 \mathrm{E}-4 \\ 3 & 3 & 1.104 \mathrm{E}-4\end{array}$

The ${ }^{252} \mathrm{Cf}$ source $\left(2.5 \times 10^{4} \mathrm{n} / \mathrm{s}\right)$ is automatically transferred from the shielded location shown in Fig. 11 to the drum by means of a Teleflex cable and Compumotor drive system. 5 Figure 12 shows the AS transfer motor. At the stopping point under the drum, a 5-cm-thick nickel reflector reflects additional source neutrons into the drum. On the side of the drum, 5-8 cm-thick graphite reflectors are used for the same purpose.

It is necessary to measure an empty drum at the time of calibration, and the resulting $R_{0}$ value is stored in the computer for subsequent data evaluation.

Each unknown drum is placed into the counter, the door is closed, and the AS measurement is performed for $\sim 3 \mathrm{~min}$. The ${ }^{252} \mathrm{Cf}$ source is automatically removed from the detector and an $\sim 10$-min passive neutron measurement completes the assay. All of the time intervals are adjustable in the computer parameter files. 


\section{ADD-A-SOURCE}

TRANSFER SYSTEM

(cont.)

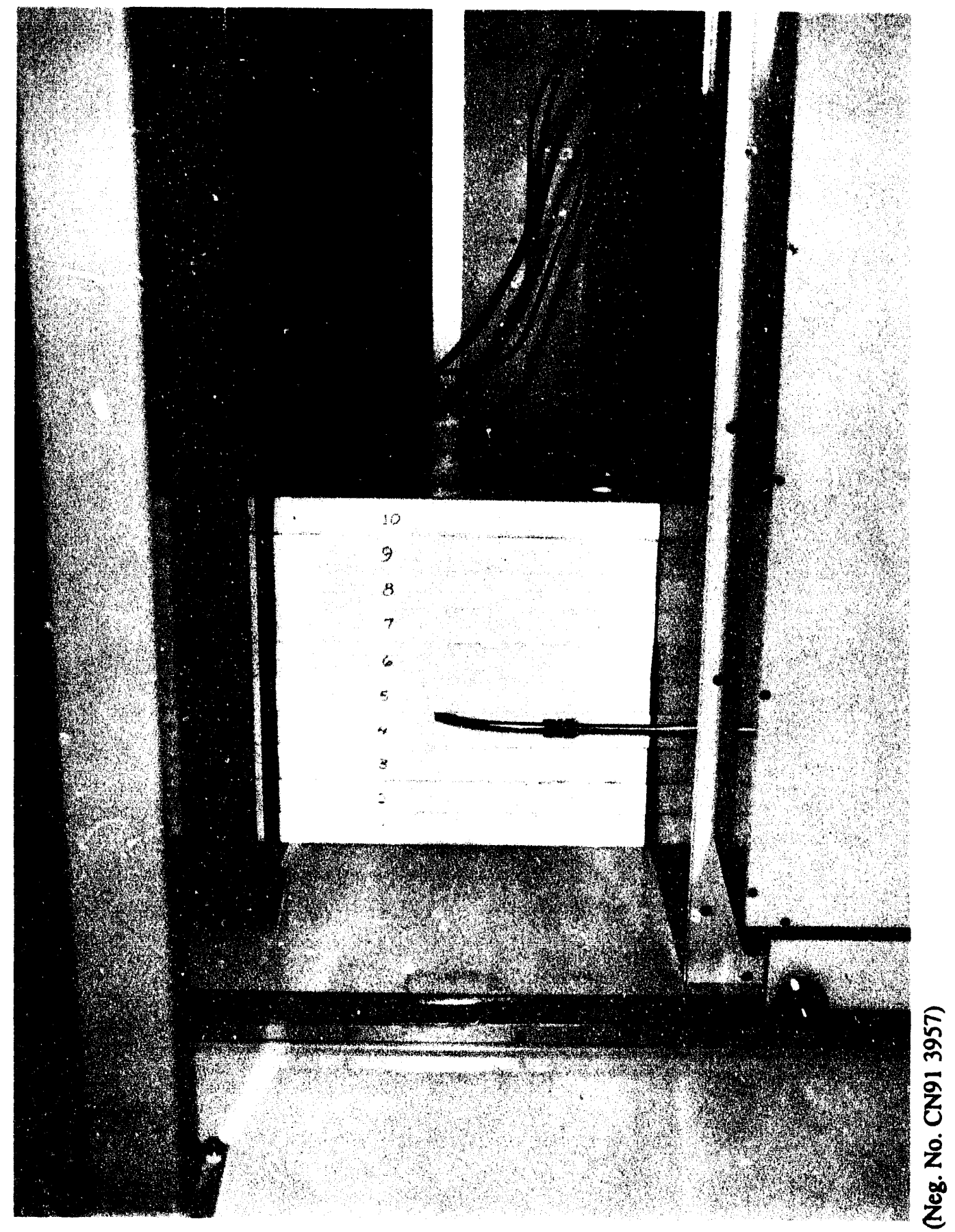

Fig. 11. Photograph of the AS neutron shield positioned on the side of the detector. 


\section{ADD-A-SOURCE}

TRANSFER SYSTEM

(cont.)

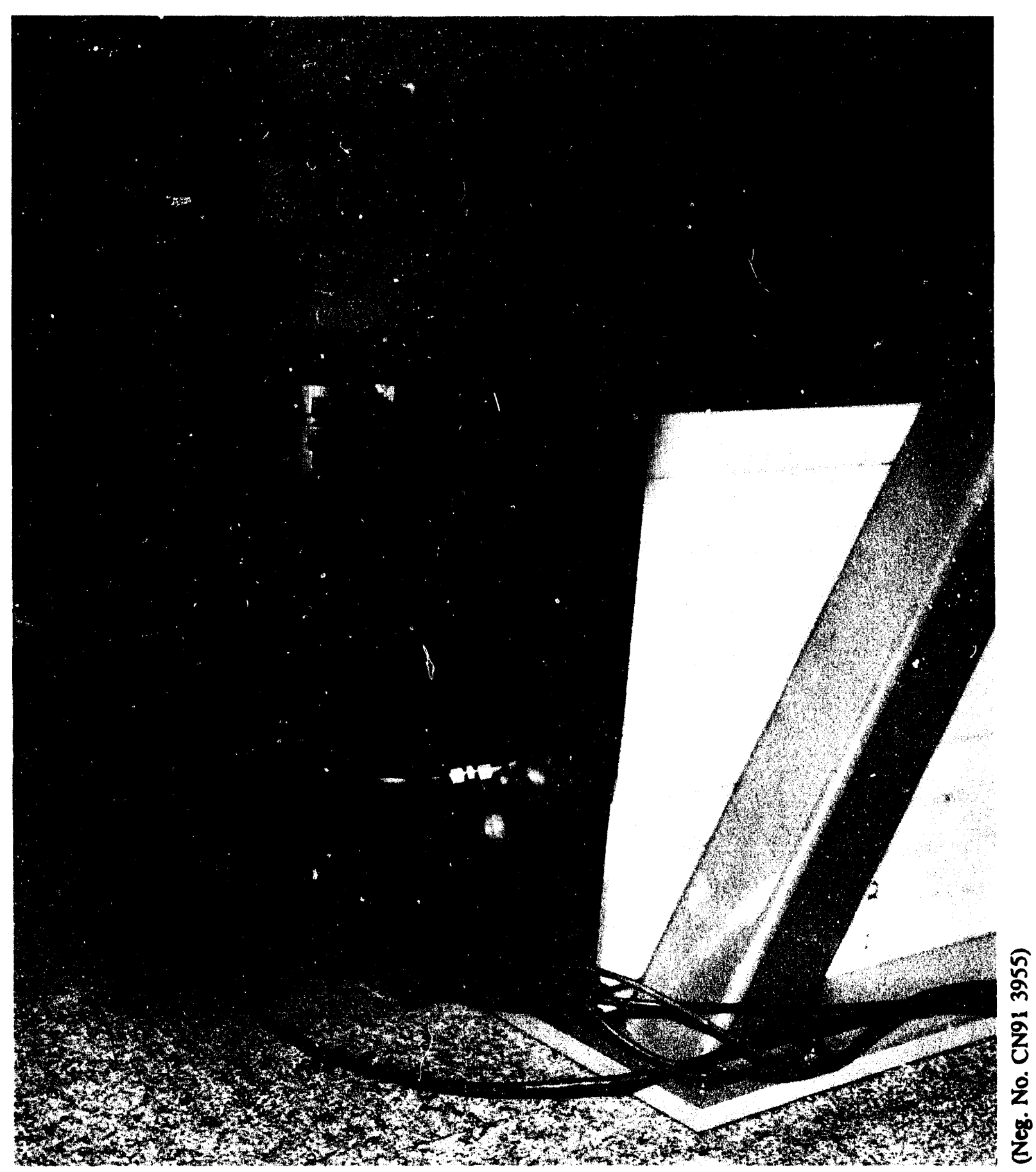

Fig. 12. Photograph of the Compumotor and teleflex transfer system on the back of NBC for the transfer of the AS. 
To evaluate the error in using the AS correction for the matrix materials listed in Table IV we used the fitted function $f(x)$ to give

$C F=1+f(x)$.

All of the measured $R$ values were normalized to the empty drum case and corrected by $C F$.

The ratios and corrected results are listed in Table VIII and illustrated in Fig. 13. The $C F$-corrected reals deviate from the empty drum with a standard deviation of only $\pm 1.7 \%$.

Table VIII. Add-a-Source Matrix Correction for 200- $\ell$ Drums

\begin{tabular}{|l|c|c|c|l|}
\hline \multicolumn{1}{|c|}{ Sample } & $\begin{array}{c}\text { Volume Average } \\
R_{0} / R\end{array}$ & Relative & $\begin{array}{c}\text { Correction Factor } \\
C F\end{array}$ & $\begin{array}{l}\text { Relative } \\
R(\text { corr. })\end{array}$ \\
\hline Empty Drum & 1.000 & 1.000 & 0.978 & 0.978 \\
\hline Vermiculite and Borax & 0.988 & 1.012 & 0.979 & 0.990 \\
\hline Paper-1 & 1.043 & 0.959 & 1.026 & 0.984 \\
\hline Paper-2 & 1.048 & 0.954 & 1.013 & 0.967 \\
\hline Wood & 1.107 & 0.904 & 1.103 & 0.997 \\
\hline Boron Glass & 1.037 & 0.964 & 1.048 & 1.010 \\
\hline Poly Shavings & 1.050 & 0.953 & 1.073 & 1.022 \\
\hline Poly Tubes & 1.763 & 0.567 & 1.798 & 1.020 \\
\hline Vermiculite + Poly Beads, 29.5 kg & 1.569 & 0.637 & 1.536 & 0.979 \\
\hline Vermiculite + Poly Beads, 59.1 kg & 2.924 & 0.342 & 2.914 & 0.996 \\
\hline Concrete + Poly Shavings & 1.112 & 0.900 & 1.124 & 1.011 \\
\hline Concrete + Paper & 1.039 & 0.962 & 1.036 & 0.997 \\
\hline \multicolumn{2}{|l}{} & & 1 sigma $=$ & $1.70 \%$ \\
\hline \hline
\end{tabular}

These same drums (except for wood and concrete) were used to determine the $f(x)$ function so the results show the scatter of our $C F$ calibration. However, after the $C F$ calibration was established, trums filled with concrete plus paper, concrete plus polyethylene, and wood were measured as unknowns and the corrected response $(R \cdot C F)$ was within $1 \%$ of the empty-drum case. A typical drum of organic waste is expected to have a hydrogen loading that is equivalent to $\rho_{\mathrm{CH}_{2}}$ $\sim 0.014 \mathrm{~g} / \mathrm{cm}^{3}$, and thus the correction factor will be smaller than the present calibration range.

Future work will include additional matrix materials to help establish the accuracy of the AS method for a variety of matrix materials. 


\section{MATRIX STUDY RESULTS}

(cont.)

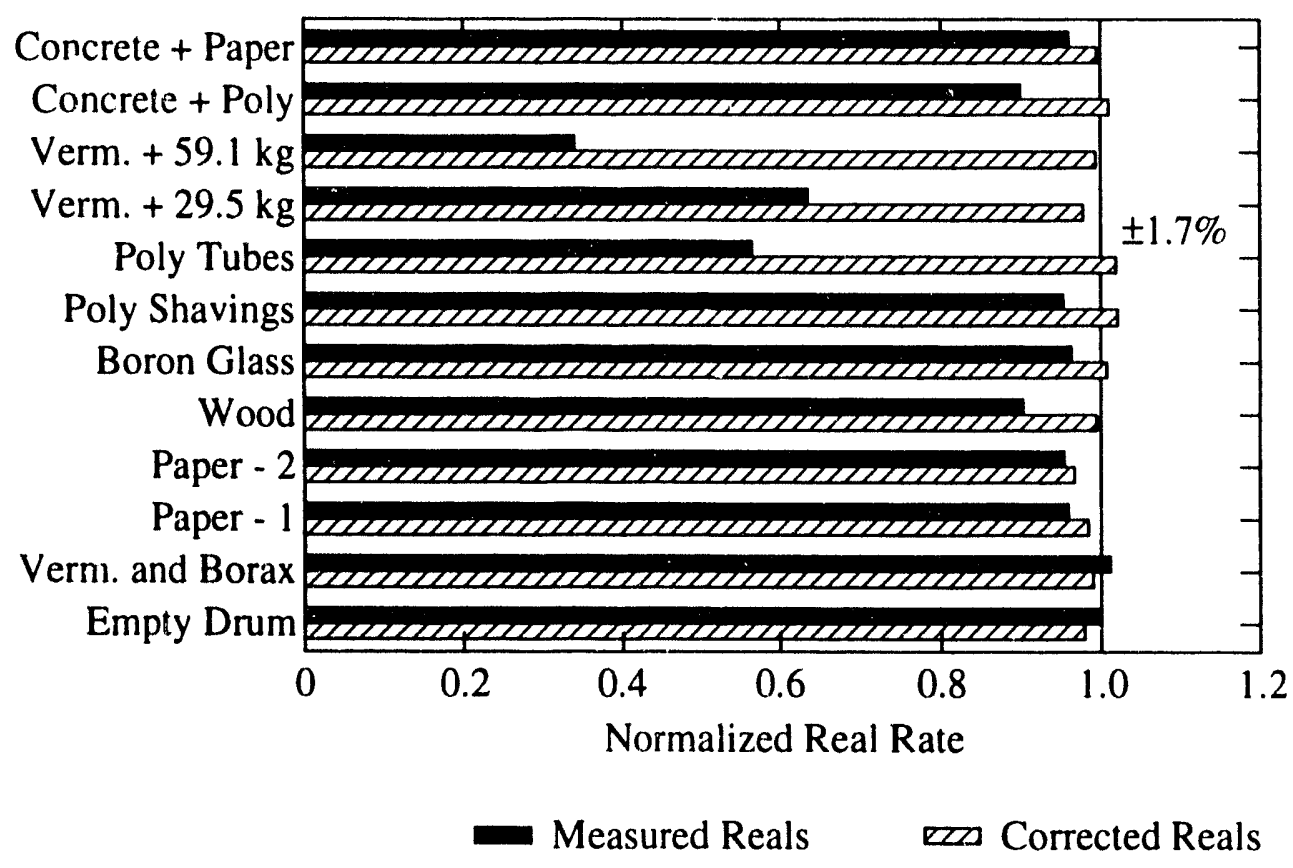

Fig. 13. The measured reals and the AS CF-corrected reals for various matrix materials in 200- $\ell$ drums.

PRECALIBRATION
Calibration measurements using small plutonium samples and MOX pellets were made at Los Alamos TA-35 before the installation of NBC at TA-55. The calibration range of interest for the waste drums is from zero to a few hundred grams of plutonium. Additional calibration measurements were performed at TA-55 after installation.

The specifications for the MOX pellets that we used for the Los Alamos calibration are listed in Table IX and the plutonium powder standards are listed in Table X. The calibrations were performed in an empty drum. 


\section{PRECALIBRATION}

(cont.)

Table IX. MOX Pellet 240Pu-eff Corrected to $3 / 19 / 93$

\begin{tabular}{|c|c|c|c|c|c|c|c|}
\hline \multicolumn{2}{|c|}{} & \multicolumn{5}{|c|}{ Weight \% relative to total plutonium mass } & \\
\hline Sample ID & Total $\mathrm{Pu}(\mathrm{g})$ & 238 & 239 & 240 & 241 & 242 & $\mathrm{~g}$ 240Pu-eff \\
\hline $\mathrm{A} 1-066$ & 0.1525 & 0.0846 & 88.4881 & 10.3149 & 0.8211 & 0.2953 & 0.0168 \\
\hline $\mathrm{A} 1-081$ & 0.5073 & 0.0846 & 88.4881 & 10.3149 & 0.8211 & 0.2953 & 0.0559 \\
\hline $\mathrm{A} 1-078$ & 0.8055 & 0.0846 & 88.4881 & 10.3149 & 0.8211 & 0.2953 & 0.0888 \\
\hline $\mathrm{A} 1-089$ & 0.2264 & 0.2329 & 77.9335 & 18.9059 & 1.6844 & 1.2434 & 0.0489 \\
\hline $\mathrm{A} 1-119$ & 0.2649 & 0.0513 & 87.2169 & 11.8545 & 0.6647 & 0.2127 & 0.0327 \\
\hline \hline
\end{tabular}

Table X. SGS Can Standards Corrected to 3/19/93

\begin{tabular}{|l|c|c|c|c|c|c|c|}
\hline & \multicolumn{5}{|c|}{ Weight \% relative to total plutonium mass } & \\
\hline Sample ID & Total Pu (g) & 238 & 239 & 240 & 241 & 242 & $\mathrm{~g}$ 240Pu-eff \\
\hline STDSGA10 & 9.9970 & 0.0061 & 96.3390 & 3.5610 & 0.0756 & 0.0180 & 0.3605 \\
\hline STDSGCAL20 & 20.0070 & 0.0061 & 96.3390 & 3.5610 & 0.0756 & 0.0180 & 0.7216 \\
\hline STDSGA30 & 29.9770 & 0.0061 & 96.3390 & 3.5610 & 0.0756 & 0.0180 & 1.0811 \\
\hline STDSGC30 & 29.9790 & 0.0061 & 96.3390 & 3.5610 & 0.0756 & 0.0180 & 1.0812 \\
\hline \hline
\end{tabular}

TA-35 RESULTS
Because of the geometric variation of the counting efficiency, we used several positions for the standards and we used the volume averaged rates.

Table XI gives the volume averaged reals rates for the standards and Fig. 14 gives a plot of $R$ vs the ${ }^{240} \mathrm{Pu}$-eff mass where

${ }^{240} \mathrm{Pu}-\mathrm{eff}=2.52{ }^{238} \mathrm{Pu}+{ }^{240} \mathrm{Pu}+1.68{ }^{242} \mathrm{Pu}$ 
TA-35 RESULTS

(cont.)

Table XI. Initial Plutonium Calibration Measured at TA-35 Bldg. 27

\begin{tabular}{|l|c|c|c|c|c|}
\hline Sample ID & Time (s) & g 240Pu-eff & Reals/s & sigma R & Reals/s - g 240Pu-eff \\
\hline $66+78+119$ & 9000 & 0.138 & 2.492 & 0.022 & 18.06 \\
\hline $66+78+81+89+119$ & 9000 & 0.243 & 4.298 & 0.031 & 17.69 \\
\hline STDSGA10 & 4800 & 0.3605 & 6.015 & 0.109 & 16.69 \\
\hline STDSGCAL20 & 3600 & 0.7217 & 12.437 & 0.174 & 17.23 \\
\hline STDSGA30 & 3600 & 1.0813 & 19.139 & 0.292 & 17.70 \\
\hline STDSGA30+ STDSGC30 & 2400 & 2.1626 & 39.345 & 0.715 & 18.19 \\
\hline \hline
\end{tabular}

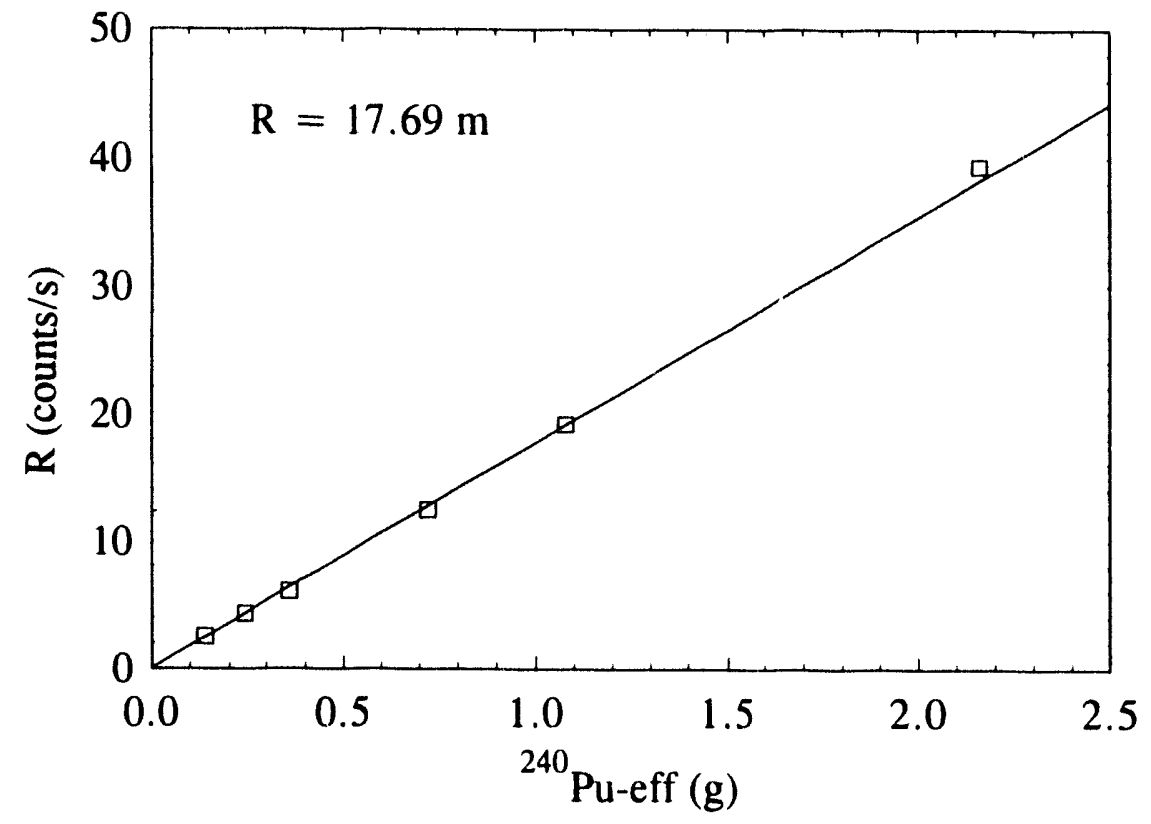

Fig. 14. Preliminary calibration curve for $(C F) R$ vs the ${ }^{240} P u$-eff mass for MOX pellets at Los Alamos. 


\section{TA-35 RESULTS}

(cont.)

TA-55 CALIBRATIONS
There is negligithle multiplication in the standards so we fitted a linear cos lion line that went through the origin. The Deming fitted callibration line is

$R$ (corr.) $=a m+b$,

where $m$ is the ${ }^{240} \mathrm{Pu}$-eff mass and

$a=17.69 \mathrm{counts} / \mathrm{s} \cdot \mathrm{g} 240 \mathrm{Pu}-\mathrm{eff}$., and

$b=6.42 \times 10^{-5}$.

When matrix material is in the drum, the measured reals are corrected by

$R($ corr $)=R($ meas $) C F$,

- $\quad$ before they are fitted to the calibration line. The $C F$ correction factor is applied to both the calibration standards and the assay samples. Thus, any error in $C F$ is limited to matrix differences between the standards and the unknowns.

After the NBC was moved from TA-35 to TA-55 at LANL, the system was recalibrated using TA-55 standards. The efficiency change after the move was negligible.

Table XII gives the specifications for the TA-55 (PF-4 Count Room) standards. The mass values are about an order of magnitude larger than the standards used at TA-35.

Table XII. Standards and Data for Calibration at TA-55 PF-4 Count Room

\begin{tabular}{|l|c|l|c|c|c|c|c|}
\hline \multicolumn{2}{|c|}{} & \multicolumn{5}{|c|}{ Weight \% relative to total plutonium mass } & \\
\hline Sample ID & Total Pu (g) & 238 & 239 & 240 & 241 & 242 & 240 Pu-eff $(\mathrm{g})$ \\
\hline STDR3 & 20.93 & 0.00122 & 94.073 & 5.765 & 0.129 & 0.0021 & 1.22 \\
\hline STD3 & 60.05 & 0.0298 & 91.993 & 7.617 & 0.283 & 0.077 & 4.7 \\
\hline STD4 & 59.89 & 0.0175 & 93.501 & 6.327 & 0.129 & 0.025 & 3.84 \\
\hline STD6 & 119.76 & 0.0175 & 93.501 & 6.327 & 0.129 & 0.025 & 7.68 \\
\hline STD8 & 239.58 & 0.0175 & 93.501 & 6.327 & 0.129 & 0.025 & 15.37 \\
\hline \hline
\end{tabular}




\section{TA-55 CALIBRATIONS}

(cont.)
The standards are cans of $\mathrm{PuO}_{2}$ powder with no attempt to dilute the $\mathrm{PuO}_{2}$ through the $200-\ell$ volume.

Table XIII gives the measurement results for the TA-55 standards and Fig. 15 shows a fit of the data using a quadratic function.

Table XIII. TA-55 Measurement Results

\begin{tabular}{|l|l|l|l|l|l|}
\hline Standard ID & Reals/s & sig Reals & Totals/s & sig Totals & Time (s) \\
\hline STDR3 & 21.032 & 0.327 & 714.1 & 0.51 & 6000 \\
\hline STD4 & 69.573 & 0.733 & 2389.7 & 0.78 & 6000 \\
\hline STD6 & 149.225 & 1.711 & 4204.5 & 1.46 & 3000 \\
\hline Background & 0.414 & 0.084 & 756.2 & 0.23 & 9000 \\
\hline \hline
\end{tabular}

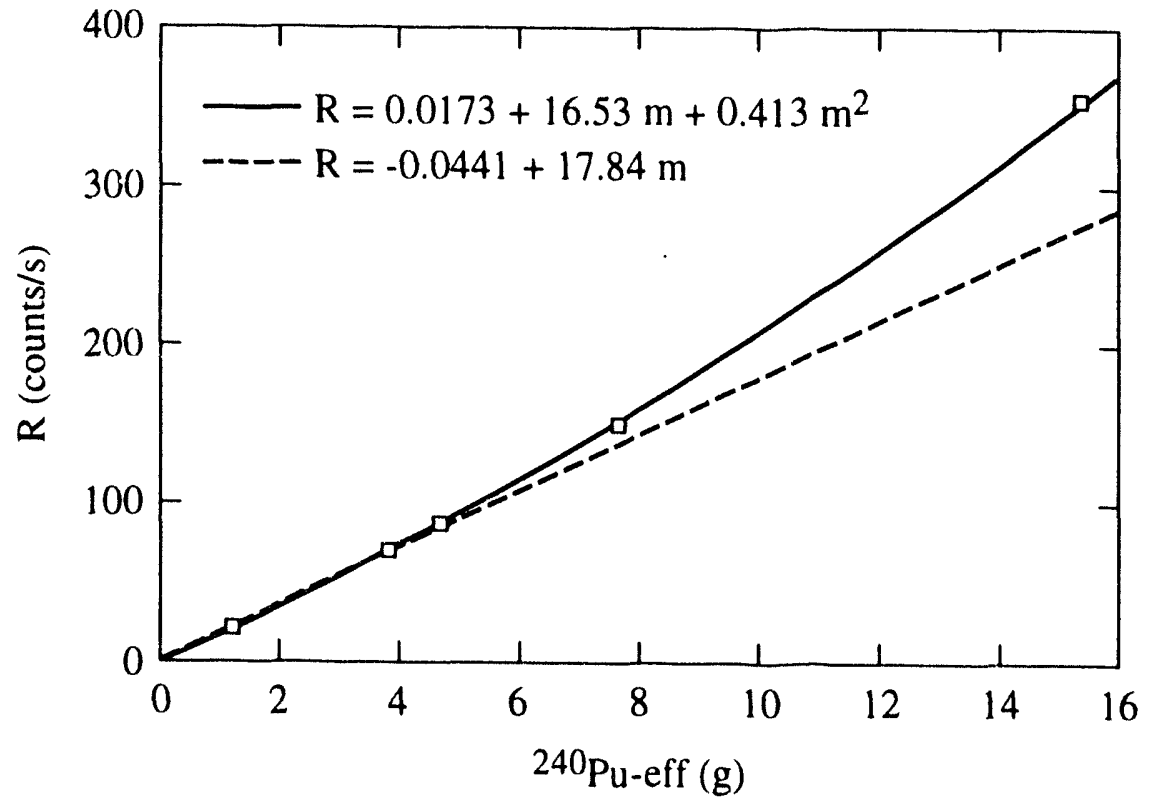

Fig. 15. Calibration curve for NBC after the installation at TA-55. The lower linear curve is the appropriate calibration for plutonium distributed in a 200- $\ell$ drum. 


\section{TA-55 CALIBRATIONS} (cont.)

MULTIPLICATION

DETECTABILITY LIMIT
The $\mathrm{PuO}_{2}$ powders are concentrated in the small cans so there is significant multiplication for the higher mass values. However for normal waste drums, the plutonium is spread over a much larger volume than the standard cans so the actual multiplication is negligible. Thus, we should use the straight line fit through the smallest two standards that gives a slope of 17.84 counts/s $\cdot g$ 240Pu-eff. This compares well with the TA-35 small-mass standards that gave a calibration slope of 17.64 .

For the normal NBC application to $200-\ell$ drums using the add-a-source software (ADDASRC), there is no significant neutron multiplication $(M=1)$ and the assay results are based on the $C F$-corrected reals rates (no multiplication correction). The AS correction changes the $R$ rates but not the $T$ rates, so the $C F$ invalidates any subsequent multiplication corrections.

However, if a high-mass multiplying sample is measured in $\mathrm{NBC}$, the normal neutron coincidence counter software (NCC) can be used and the multiplication-corrected result is available. For this type of application, we have measured the multiplication constant for NBC using the small pellets listed in Table IX.

The result was

$$
\rho_{0}=\frac{R}{T}(1=\alpha)=0.096
$$

where $\alpha$ is the ratio of $(\alpha, \mathrm{n}) /$ spontaneous fission neutrons. The coincidence gate was set at $128 \mu \mathrm{s}$ and if the gate is reduced to $64 \mu \mathrm{s}, \rho_{0}$ will be reduced by a factor of $\sim 1.4$.

The detectability limit $d$ (in grams of ${ }^{240} \mathrm{Pu}$ ) at 3 standard deviations above background was calculated for the counter using the calibration curve and the equation

$d=(3 / a) \cdot\left(\frac{B+a d}{t}\right)^{1 / 2}$,

where 


\section{DETECTABILITY LIMIT}

(cont.)

$$
\begin{aligned}
a= & \text { response of counter in counts } /(\mathrm{s} \bullet \mathrm{g} 240 \mathrm{Pu})=17.64, \\
B= & \text { room background reals rate }=0.096 \text { counts } / \mathrm{s} \\
& \text { (shielded location), and } \\
t= & \text { counting time }=1000 \mathrm{~s} .
\end{aligned}
$$

For the coincidence mode, $d=1.89 \mathrm{mg}$ of $240 \mathrm{Pu}$ in the TA-35 shielded location; however, the detectability limit after installation will depend on the background rate at TA-55. Figure 16 shows a graph of the detectability limit vs the neutron coincidence background for NBC.

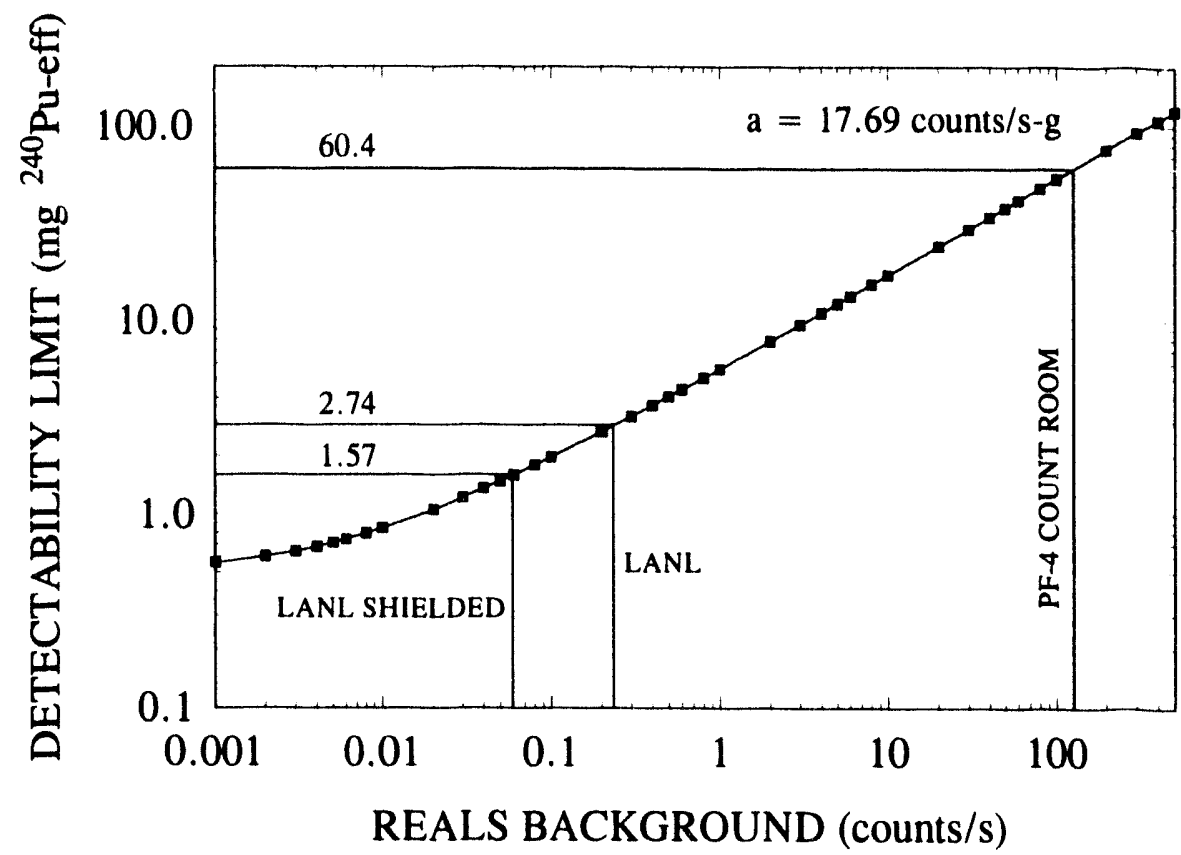

Fig. 16. Calculated NBC detectability limit vs neutron coincidence background for a 1000-s measurement time.

The coincidence background is primarily from cosmic-ray spallation except for the case of a high totals background rate. When the totals rate $T$ is high, then the accidental coincidence rate $A$ can become large. The accidental rate can be calculated from

$A=(T)^{2} G$,

where $G=$ the gate length in seconds. 


\section{DETECTABILITY LIMIT} (cont.)
HYDROGEN DETERMINATION
For example, a high totals background rate of 500 counts/s gives

$A=(500)^{2}\left(128 \times 10^{-6}\right)=32$ counts/s,

that is much higher than the cosmic-ray rate of $\sim 0.2$ counts/s. For this example, a $64-\mu$ s gate should be used rather than a $128-\mu$ s gate. Additional external $\mathrm{CH}_{2}$ shielding is the most effective method to reduce a high room background (totals rate). For example $10 \mathrm{~cm}$ of $\mathrm{CH}_{2}$ will reduce the background by a factor of $\sim 10$, and this gives a factor of $\sim 100$ reduction in the accidental coincidence rate. ${ }^{6}$

The detectability limit is a function of the neutron coincidence background, and we have reduced our background by a factor of $\sim 1.8$ by eliminating the cosmic-ray spallation events with high multiplicity. The cosmic-ray events can be counted as prompt charged-particle reactions in the detector tubes or as spallation-source neutrons that extend in time over the slowing-down time of the detector body.

The predelay $(4.5 \mu \mathrm{s})$ eliminates the first category because the events are short lived and the predelay vetoes them from the coincidence gate. The spallation neutrons fall within the coincidence gate but often with high multiplicity. We use the data collection software to isolate the high-multiplicity events and to eliminate them from the data averages. We are currently using statistical techniques to accomplish this. In the future, we could use multiplicity electronics to eliminate these types of cosmic-ray events.

Because the neutron scattering, moderation, and absorption in the drum are dominated by the hydrogen content, we can use the AS measurement to determine the approximate hydrogen content in a drum. The data giver in Table XIV have been graphed in Fig. 17 with the AS perturbation $(x)$ as a function of the hydrogen density $\left(\rho_{\mathrm{H}}\right)$. For comparison, full density $(\rho=1) \mathrm{H}_{2} \mathrm{O}$ has $\rho_{\mathrm{H}}=0.11 \mathrm{~g} / \mathrm{sm}^{3}$. 
HYDROGEN DETERMINATION

(cont.)

Table XIV. Add-a-Source Perturbation as a Function of Hydrogen Density

\begin{tabular}{|l|c|c|}
\hline \multicolumn{1}{|c|}{ Sample } & Hydrogen Density & AS Perturbation $(x)$ \\
\hline Empty & 0 & 0 \\
\hline Polyethylene Shavings & 0.0086 & 0.104 \\
\hline $\begin{array}{c}\text { Vermiculite }+ \\
29.5 \mathrm{~kg} \text { of Poly Beads }\end{array}$ & 0.0222 & 0.496 \\
\hline Polyethylene Tubes & 0.031 & 0.649 \\
\hline $\begin{array}{c}\text { Vermiculite }+ \\
59.1 \mathrm{~kg} \text { of Poly Beads }\end{array}$ & 0.0444 & 1.067 \\
\hline \hline
\end{tabular}

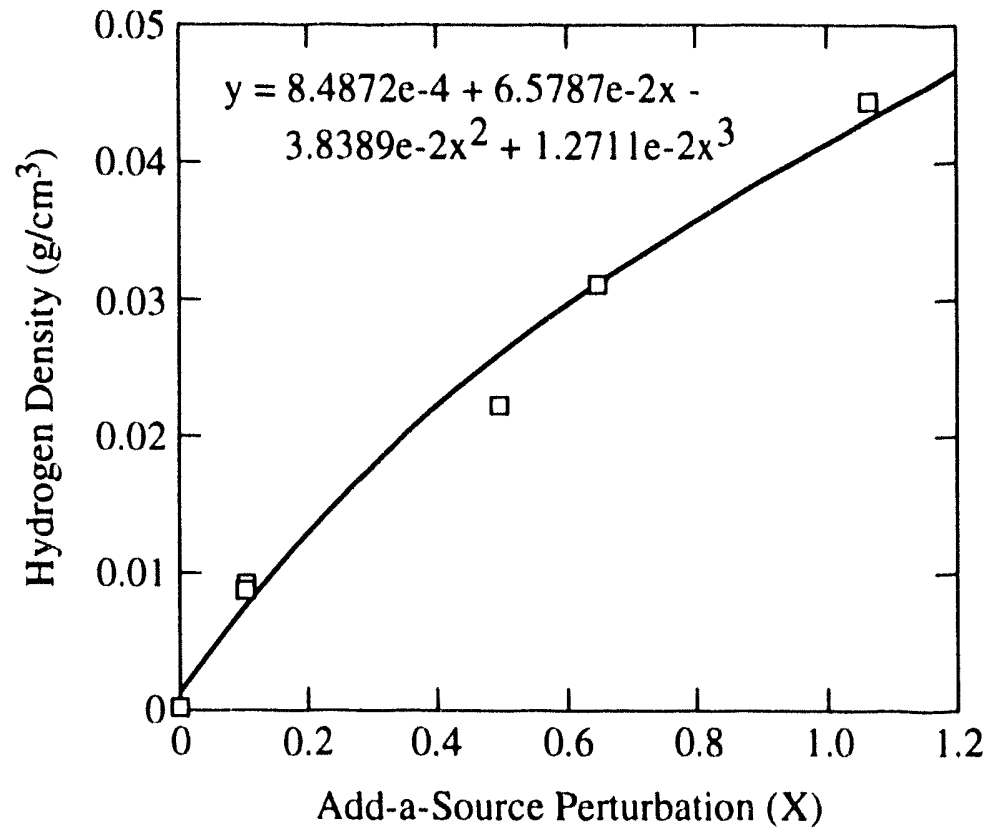

Fig. 17. AS perturbation ( $x$ ) as a function of hydrogen density in 200- $\ell$ drums containing $\mathrm{CH}_{2}$. 


\section{HYDROGEN DETERMINATION}

(cont.)
For applications of AS to hydrogen determination, calibrations should be performed using a known hydrogen loading in the matrix materials of interest.

Thermal-neutron absorbers, such as boron, in the matrix have almost no effect on the measurement because the AS perturbation $x$ is based on the ratio of $R$ values. The 64 to $128-\mu$ s coincidence gate for $R$ eliminates all neutrons that are at thermal energy inside the drum because the flight time to the ${ }^{3} \mathrm{He}$ tubes is longer than the coincidence gate.

The method of neutron moderation has been used in many fields (for example, borehole logging) to determine the amount of hydrogen. The present application of AS to determine the hydrogen is new in that it uses neutron coincidence counting. This gives an important improvement to the hydrogen measurement because the coincidence timing criteria prevent the results from being dependent on the impurities that absorb thermal neutrons.

NORMALIZATION PROCEDURE The standard method of using a ${ }^{252} \mathrm{Cf}$ source to correct for efficiency changes in the detector system should not be used when using the AS procedure. The AS correction factor $(C F)$ picks up any efficiency changes in the detector system and automatically corrects the final result. However, the correction is based on the assumption that the efficiency change was from the matrix rather than the detector, thus the $C F$ calibration would need to be rechecked.

The NBC provides a sensitive (19.3\% efficiency) and accurate method to measure plutonium in $200-\ell$ waste drums. Other samples such as boxes that fit into the sample cavity can be measured as well as the drums. The sensitivity of the system will depend on the room background and the cosmicray spallation background at the measurement location. The accuracy will depend on the particular matrix type and the plutonium mass level.

For the typical drum-matrix loadings, the detector has been optimized to be insensitive to matrix changes. The detector wall thickness was chosen to give approximately the same counting rate for an empty drum and a drum containing $20 \mathrm{~kg}$ of combustible wastes such as paper and rags. As the matrix density increases, the AS correction is effective for correcting the measurement back to the calibration condition. 


\section{SUMMAR Y}

(cont.)
The AS correction significantly improves the final assay accuracy as illustrated in Fig. 13. The AS feature also gives the capability to flag outlier samples that contain an unexpected matrix. If neutron shielding material is present in the drum, the AS procedure picks up the problem with good sensitivity. 


\section{REFERENCES}

1. David W. Miller and Norbert Ensslin, "Drum Counter Design and Operation Manual," Los Alamos National Laboratory report LA-11892-M (July 1990).

2. H. O. Menlove, et al. "WDAS Operation Manual including the Add-a-Source Function," Los Alamos National Laboratory report LA-12292-M (April 1992).

3. H. O. Menlove and J. E. Swansen, "A High-Performance Neutron Time-Correlation Counter," Nucl. Technol. 71, 497-505 (November 1985).

4. J. E. Swansen, P. R. Collinsworth, and M. S. Krick, "Shift-Register Coincidence Electronics System for Thermal Neutron Counters," Los Alamos Scientific Laboratory report LA-8319-MS (April 1980). Also in Nucl. Instrum. Methods 176 (3), 555-565 (1980).

5. Phillip M. Rinard, "Shuffler Instruments for the Nondestructive Assay of Fissile Materials," Los Alamos National Laboratory report LA-12105 (May 1991).

6. H. E. Hootman, "Estimation of ${ }^{252}$ Cf Shielding Requirements," E. I. DuPont de Nemours \& Co., Savannah River Laboratory, Aiken, South Carolina, report TID-4500, UC-34 (April 1970). 

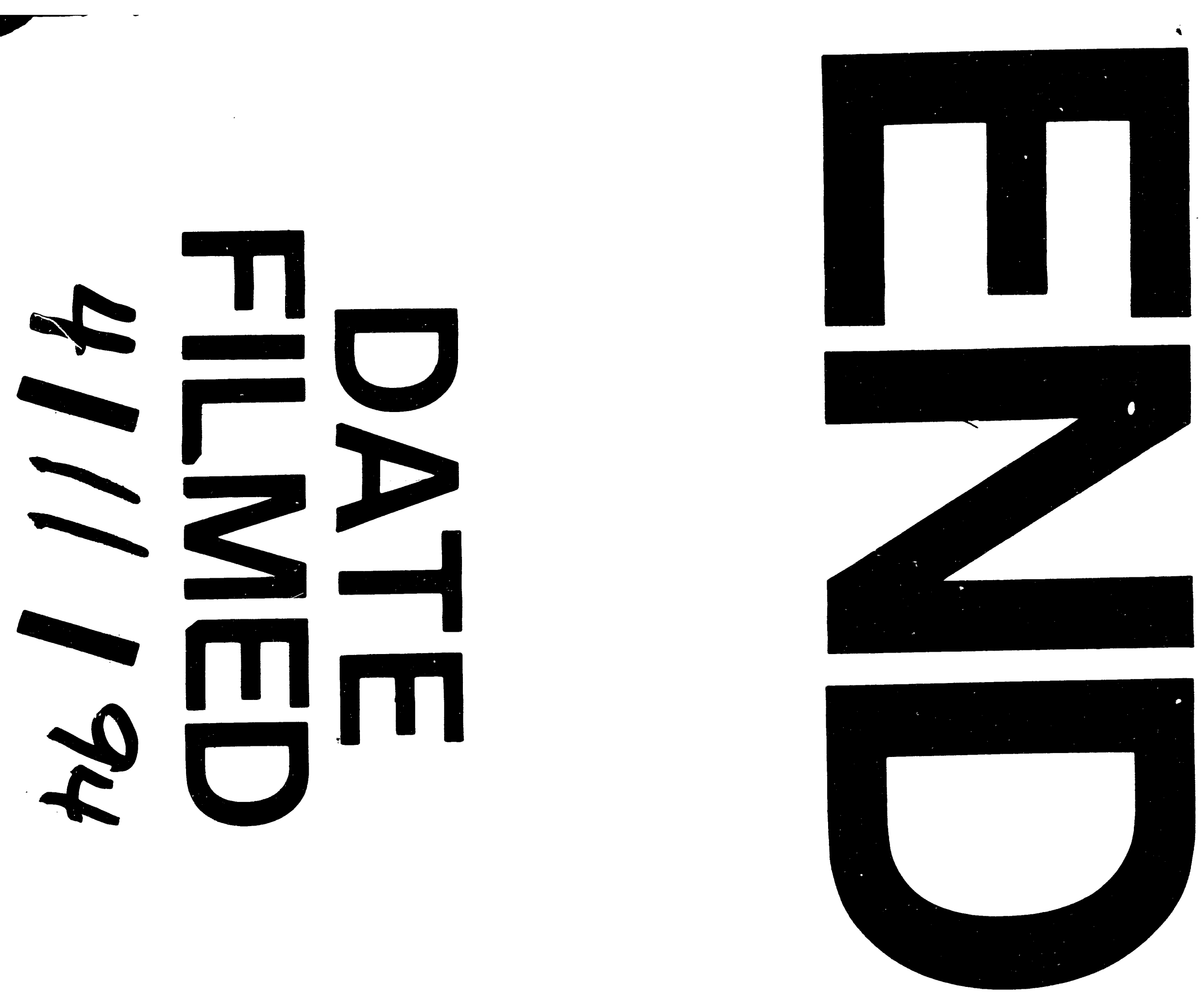